\title{
SIMPLIFIED ELECTRICITY MARKET MODELS WITH SIGNIFICANT INTERMITTENT RENEWABLE CAPACITY: EVIDENCE FROM ITALY
}

\author{
Christoph Graf \\ Federico Quaglia \\ Frank A. Wolak \\ Working Paper 27262 \\ http://www.nber.org/papers/w27262
NATIONAL BUREAU OF ECONOMIC RESEARCH
1050 Massachusetts Avenue
Cambridge, MA 02138
May 2020

We are indebted to Severin Borenstein, Jim Bushnell, Franz Wirl, as well as the participants of the POWER conference at UC Berkeley for their valuable comments. The views expressed herein are those of the authors and do not necessarily reflect the views of the National Bureau of Economic Research.

NBER working papers are circulated for discussion and comment purposes. They have not been peer-reviewed or been subject to the review by the NBER Board of Directors that accompanies official NBER publications.

(C) 2020 by Christoph Graf, Federico Quaglia, and Frank A. Wolak. All rights reserved. Short sections of text, not to exceed two paragraphs, may be quoted without explicit permission provided that full credit, including (C) notice, is given to the source. 
Simplified Electricity Market Models with Significant Intermittent Renewable Capacity: Evidence from Italy Christoph Graf, Federico Quaglia, and Frank A. Wolak

NBER Working Paper No. 27262

May 2020

JEL No. Q4,Q41

\begin{abstract}
Using hourly offer curves from the Italian day-ahead market and the real-time re-dispatch market for the period January 1, 2017 to December 31, 2018, we show how thermal generation unit owners are able to profit from differences between a simplified day-ahead market design that ignores system security constraints as well as generation unit operating constraints, and real-time system operation where these constraints must be respected. We find that thermal generation unit owners increase or decrease their day-ahead offer prices depending on the probability that their final output will be increased or decreased relative to their day-ahead schedules because of realtime operating constraints. First, we estimate generation unit-level models of the probability of each of these outcomes conditional on forecast demand and renewable production in Italy and neighboring countries. Our most conservative estimate of the impact of a change in the probability a unit owner will have its day-ahead schedule increased in the real-time re-dispatch market implies a day-ahead offer price increase of $5 \mathrm{EUR} / \mathrm{MWh}$ if this probability changes by 0.1 . If the probability of a day-ahead schedule decrease rises by 0.1 the unit owner's offer price is predicted to be $6 \mathrm{EUR} / \mathrm{MWh}$ less. Over our sample period, we find that the economic re-dispatch cost averaged approximately $15 \%$ of the total cost of energy consumption valued at the day-ahead price.
\end{abstract}

Christoph Graf

Department of Economics

Stanford University

Stanford, CA 94305

cgraf@stanford.edu

Federico Quaglia

Terna S.p.A.

Viale Egidio Galbani, 70

Rome 00156

Italy

federico.quaglia@terna.it
Frank A. Wolak

Department of Economics

Stanford University

Stanford, CA 94305-6072

and NBER

wolak@zia.stanford.edu 


\section{Introduction}

An increasing number of regions have ambitious renewable energy goals that have primarily been met by investments in wind and solar generation capacity. The growing share of energy produced from these intermittent renewable sources has significantly increased the challenges faced by system operators in maintaining demand and supply balance in realtime while respecting grid security constraints. Although wind and solar generation units produce energy at zero marginal cost, this energy is only produced when the underlying resource is available. The difference between system demand and intermittent renewable energy production must be supplied by dispatchable generation resources typically powered by fossil fuels.

There are two major reasons why a significant amount of intermittent renewable generation capacity creates challenges for system operators. First, renewable energy production can both appear and disappear very quickly. For example, in a region with a significant amount of solar photovoltaic capacity, typically there is a rapid increase in energy production in the morning when the sun rises and a rapid decline in energy production when the sun sets in the evening. This means that dispatchable generation capacity must ramp down rapidly early in the day and ramp up quickly at the end of the day, which implies a number of these generation units may need to start-up and shutdown each day. Second, high shares of intermittent renewable generation capacity can necessitate operating a substantial amount of dispatchable generation capacity at their minimum operating level during a portion of the day to ensure that there is adequate dispatchable generation capacity on-line to respond to expected or unexpected reductions in renewable energy production during the day.

Figure 1 demonstrates the tremendous increase in the range of realized hourly output levels for dispatchable generation each hour of day in Germany between 2007 to 2018, when the annual share of wind and solar energy production went from approximately $7 \%$ to $25 \%$. Each colored box in the figure gives the $25^{t h}, 50^{\text {th }}$ and $75^{\text {th }}$ percentile of values of the difference between the system demand and renewable energy production for an hour of the day, across 
all days in the year. The lower end of each arrow is the $1^{\text {th }}$ percentile and the upper end of the arrow is the $99^{\text {th }}$ percentile of the daily distribution of net demand (system demand less renewable energy production) for that hour of the day. In 2007, the difference between the $99^{\text {th }}$ and $1^{\text {th }}$ percentiles was less than $30,000 \mathrm{MWh}$, whereas by 2018 this range was more than 60,000 MWh for a number of hours of the day. Both the wide range of realized values of the net demand during each hour of the day and the substantially lower $1^{\text {th }}$ percentile in 2018 relative to 2007 imply that there will be many more grid reliability constraints on how dispatchable generation units can operate in 2018 relative to 2007.

The wider range of realized hourly net demand levels is not just a German phenomenon. We also find it for Italy. In Figure 2, Panel (a), we show that the net demand uncertainty has increased especially during the night. Furthermore, the hourly distribution of realized net demand values during each hour of the day has shifted down. The picture gets even more drastic when we focus only on the region south of Tuscany (including the large islands of Sardinia and Sicily). Figure 2, Panel (b), demonstrates that the difference between the $99^{\text {th }}$ and $1^{\text {th }}$ percentiles was about 4,000 MWh, during the night hours in 2007, whereas by 2018 this range was about 8,000 MWh. The major reason for this development is that most of the wind capacity has been installed in this part of the country.

Meeting substantially more volatile hourly net demands throughout the day but also very low levels of net demands in a least cost manner requires a wholesale market design that accounts for the significantly larger number of operating constraints on generation units and the transmission network necessitated by the large share of intermittent renewable generation capacity. Electricity-markets in the United States (US) are designed to deal with many of these challenges as a result of changes made over the last two decades. The multi-settlement locational marginal pricing (LMP) market designs (Bohn et al., 1984) adopted in all formal wholesale markets in the United States account for these operating constraints in determining dispatch levels and the prices paid to generation units. ${ }^{1}$ In contrast, Europe currently has a

\footnotetext{
${ }^{1}$ Additional system security constraints are likely to be necessary to account for even in US LMP markets as the share of intermittent renewable energy increases.
} 
zonal day-ahead market for electricity, where with a few exceptions, each country is a single pricing zone.

The European day-ahead market does not model the transmission network within most countries and uses a simplified network model in the remaining countries with more than one pricing zone. In addition, this market ignores many of the operating constraints on generation units such as start-up and no-load costs and ramping constraints in operating the day-ahead market. Therefore, after day-ahead generation schedules and market prices are determined and before real-time network operation, the system operator operates a re-dispatch market which it uses to produce final schedules that are feasible given the configuration of the transmission network and meet the system security constraints for reliable real-time operation of the grid. This process requires some units to produce less than their day-ahead schedule and others to produce more during each hour of the day. This may also require that some generation schedules to be set to zero and other generation units to start up.

In the early zonal markets in the US, this two-step process of selling energy in a simplified day-ahead market followed by pay-as-offered re-dispatch market designed to make generation schedules feasible creates opportunities for generation unit owners to take advantage of their location in the transmission network or their ability to resolve some operating constraint to increase the revenues they earn. If a market participant was confident one of its generation units was likely to have its day-ahead schedule reduced, what is typically called "constraineddown," the unit would be offered into the day-ahead market at an extremely low price to ensure that it would sell energy at the market-clearing price in the day-ahead market. Then in the re-dispatch market the unit owner would agree to buy this energy back from the system operator at an extremely low price and earn the difference between the day-ahead market price and this low price times the amount of energy sold back to the system operator.

Similarly, if a market participant was confident that additional energy was needed from a generation unit in order to operate the transmission network reliably, what is typically called "constrained-up," the unit owner would offer a sufficiently high price (or not offer any 
capacity at all) into the day-ahead market to ensure that the unit was not taken. Then in the re-dispatch market the unit owner would agree to sell the necessary energy at this high offer price. In both cases, these actions are profitable for the market participant because the simplified day-ahead market allows generation schedules that are physically infeasible to be accepted in the day-ahead market and there is insufficient competition among market participants to supply the local energy reduction or local energy increase necessary to obtain feasible schedules.

In the US, this approach to exercising local market power in a zonal market with a pay-as-offered re-dispatch market is called the "INC/DEC Game" because selling additional energy in the re-dispatch market was called selling incremental (INC) energy and buying back energy in the re-dispatch market was called selling decremental (DEC) energy. Although the ability of market participants to exercise local market power through the "INC/DEC Game" was a major motivation for the transition to LMP markets throughout the US, there has not been a systematic evaluation of the frequency or cost of these activities in any US wholesale market.

Europe has operated zonal market designs similar to the initial US zonal market designs for many years without incurring significant re-dispatch costs from making generation schedules that emerge from the day-ahead market feasible. Because of more extensive transmission networks in European countries relative to the US as well as more available generation capacity, many of the system operating constraints in these countries were hardly ever binding and it was difficult to predict the conditions under which these constraints would be binding. However, in the last decade the European electricity supply industry has drastically changed as a result of substantial intermittent renewable generation investments. As a consequence many more operating constraints have become relevant and when they are binding has also become more predictable, which provides opportunities for market participants to employ the offer strategies described above.

Re-dispatch quantities and cost have been increasing throughout Europe over the last 
decade. $^{2}$ The most extreme example is Germany which faced an increase in re-dispatch quantities from about 1 TWh in 2010 to more than 15 TWh in 2017 which is about $2.5 \%$ of the country's annual electricity consumption (Hirth and Schlecht, 2019). The trajectory of the re-dispatch quantities correlates with the progress of the German Energiewende, i.e., the transformation from a primarily fossil-fuel and nuclear power-based to a intermittent renewables-dominated electricity supply industry. Progressive policies have lead to an increase in solar photovoltaic capacity from about 4 GW to 45 GW between 2007 and 2018. Wind capacity - including off-shore wind installations - has increased from about 22 GW to about $60 \mathrm{GW} .^{3}$ Although, Germany relies on a scheme where re-dispatched energy is bought and sold at generation unit-specific cost-based prices set by the energy regulator, the total cost of the re-dispatch was about 1.5 billion Euros in 2018 (Hirth and Schlecht, 2019). Nevertheless, market-based re-dispatch mechanisms have been proposed in the latest European Union Regulation and this change could significantly increase the ability of suppliers to exercise unilateral market power in the re-dispatch process. ${ }^{5}$

This paper focuses on the Italian wholesale electricity market which currently employs a market-based mechanism for its balancing and re-dispatch model. The design of the Italian day-ahead market is much closer to that of the US LMP markets than the single-pricing zone markets that exist throughout Europe because it accounts for transmission constraints between six domestic zones and four limited production zones. ${ }^{6}$ Consequently, the magnitude of the INC/DEC game problem in the Italian market is likely to be a lower bound on the magnitude of this problem for European countries that do not respect any transmission

\footnotetext{
${ }^{2}$ See https://docstore.entsoe.eu/Documents/Events/2018/BZ_report/20181015_BZ_TR_FINAL. pdf.

${ }^{3}$ See https://www.erneuerbare-energien.de.

${ }^{4} \mathrm{~A}$ regulated cost-based approach to re-dispatch has the advantage that it limits the ability of suppliers to exercise unilateral market power in the re-dispatch market, it does not completely eliminate the incentive suppliers have to increase their revenues from exploiting differences between the network model and operating constraints respected in the day-ahead market and the corresponding constraints respected in the re-dispatch market.

${ }^{5}$ See https://eur-lex.europa.eu/legal-content/EN/TXT/?uri=CELEX\%3A32019R0943, Article 13.

${ }^{6}$ The bidding zone configuration has been simplified at the beginning of 2019 .
} 
network constraints or all generation unit operating constraints in the day-ahead market. ${ }^{7}$

The purpose of this paper is to use the experience of the Italian market to study the extent to which market participants have been able to profit from differences between the zonal market model used in the day-ahead market and the real-time operating constraints that must be respected in the re-dispatch market run after the close of the day-ahead market. Specifically, we first investigate whether market participants are able to predict when their generation units will be constrained-down or constrained-up. We then demonstrate that a higher probability of being constrained down is associated with the unit owner submitting a lower offer price into the day-ahead market and a higher probability of being constrained up is associated with the unit owner submitting a higher offer price into the day-ahead market.

Our most conservative estimate of how the average day-ahead offer price markup set by thermal plants will change when the predicted probability of getting INCed in the re-dispatch market increases by 0.1 is about $5 \mathrm{EUR} / \mathrm{MWh}$. If the predicted probability of getting DECed increases from by 0.1 , the markup set by the average unit is about $6 \mathrm{EUR} / \mathrm{MWh}$ less. Our results are robust with respect to a wide range of different model specifications and estimation strategies.

We find a U-shaped relationship between the hourly re-dispatch cost and hourly demand net of intermittent renewables production. The right side of the "U" can be explained by market power in the conventional sense. Higher net demand means that there is less competition for a marginal increase of supply because most available generation capacity is required to meet this demand. The left part of the "U" implies a higher re-dispatch cost for lower levels of net demand. This illustrates a different form of market power that can happen when only a few units are required to be on-line. These units may prefer to submit offer curves into the simplified day-ahead market that are incompatible with a secure grid operation and subsequently have their day-ahead schedules increased in the re-dispatch market and receive a large incremental energy payment while others have their schedules

\footnotetext{
${ }^{7}$ Italy currently experiences situations where too few conventional units at critical locations would like to remain online to ensure stable voltage levels. Consequently a local market power situation arises.
} 
decreased in the re-dispatch market and receive a large decremental energy payment. These large re-dispatch costs on low net demand days challenge the prevailing notion that additional intermittent zero-cost renewable capacity will lead to lower average electricity prices. The thermal generation unit-level offer strategies we document during these low net demand days raises average wholesale energy costs because of the resulting INC and DEC re-dispatch payments. On a system-wide basis, we quantify the relative cost of the re-dispatch process as $15 \%$ of real-time energy demand valued at the day-ahead price for the years 2017 and 2018.

The remainder of the paper is organized as follows. We start with a description of the Italian electricity market in Section 2 followed by an in-depth description of INC/DEC strategies in Section 3. In Section 4, we describe the data and how we predict the probability that a generation unit will have its day-ahead schedule increased or decreased in the redispatch market. In Section 5, we present our empirical results showing that higher offer-price markups over marginal cost are submitted to the day-ahead market when the probability that the unit has its output increased in the re-dispatch market increases. These empirical results also demonstrate that lower offer-price markups are submitted to the day-ahead market when the probability that the unit has its output reduced in the re-dispatch market increases. We complement our results with an extensive set of robustness checks in Section 6. In Section 7 , we document the U-shaped relationship between hourly re-dispatch costs and hourly net

demand and compute the aggregate re-dispatch costs as a percentage of the annual cost of wholesale electricity over our two-year sample period. Finally, in Section 8, we conclude and discuss the implications of our results for wholesale market design.

\section{The Operation of the Italian Wholesale Market}

The Italian wholesale market of electricity consists of the European day-ahead market followed by a series of domestic intra-day market sessions, and finally the re-dispatch market. 
The day-ahead market does not procure ancillary services, only energy. The demand side of the day-ahead market in Italy pays a uniform purchase price, that is a demand-share weighted average of the day-ahead zonal prices in Italy. In the intra-day market sessions, market participants have the option to update their positions resulting from the day-ahead market-clearing or the previous intra-day market session. ${ }^{8}$ The day-ahead market as well as the intra-day markets are locational (zonal) marginal pricing markets.

The day-ahead market-clearing, gives a schedule for each unit as well as the zonal price for every hour of the next day. Shortly after clearing the day-ahead market, two out of the seven intra-day market sessions are run, still a day ahead of actual system operation. After the clearing of the second intra-day market, the first session of the re-dispatch market takes place. In the re-dispatch market, the objective is to transform the schedules resulting from the energy market-clearing into schedules that allow a secure grid operation at least cost. The mathematical program that is solved in the re-dispatch market is called a security constrained unit commitment (SCUC) problem. ${ }^{9}$

From a technical perspective the most important differences between the day-ahead (intra-day) market-clearing engine and the re-dispatch market-clearing engine are the following: (i) the zonal representation of the network is replaced by a nodal transmission grid model reflecting the physical capacity of the 220 kilovolt $(\mathrm{kV})$ and $380 \mathrm{kV}$ network elements, (ii) upward and downward reserve requirements for eligible thermal and hydro (storage) units are respected, (iii) thermal units' operational constraints are respected, (iv) voltage

\footnotetext{
${ }^{8}$ Unlike in the day-ahead market the intra-day market clears using zonal prices. However, a non-arbitrage fee due only for demand side transactions aims to eliminate incentives to arbitrage between these markets because of the different pricing rules. The fee is calculated based on the realized uniform purchase price in the day-ahead market and the cleared zonal prices in the intra-day markets.

${ }^{9}$ Between the market-clearing of the second intra-day market and real-time several re-dispatch market sessions are run. The re-dispatch market is composed of a planning session and a real-time balancing session. In the planning sessions, congestion is resolved, reserves are procured, and the system is balanced while in the real-time balancing market mainly balancing of the system and congestion management are done. Note that most fossil-fuel plants are not able to instantly increase or decrease their schedules and therefore the realtime balancing session is accompanied by a planning session that ensures that potential real-time changes are technically feasible. Note further that although each market participant is responsible for providing technically feasible schedules, i.e., the market participant bears the imbalance cost for schedule deviations at the unit level, the supplied schedules may violate other relevant grid constraints which may require a re-dispatch action.
} 
constraints are respected, ${ }^{10}$ and (v) contingencies, i.e., the failure or loss of grid elements are considered. To summarize, the optimization model that ensures a secure operation of the grid is very different from the simplified energy-only market-clearing algorithm. Finally, unlike the day-ahead and intra-day markets, the re-dispatch markets pay as offered for energy and start-ups.

These facts emphasize that the secure operation of an electric grid is more complex than just equating aggregate supply and demand. The supply of energy must be equal to the demand for energy minus net imports at every point of injection and withdrawal from the network during every instance in time. This implies that if a generation resource at a particular location is required to operate to achieve this outcome, output from resources at other locations must be decreased in order to make room for the required resource. The configuration of the transmission network or other system security constraints can significantly limit the set of units able to have their output reduced.

The real-time operation of all generation units must respect all of these operating constraints, whether or not these constraints are respected in the day-ahead or the intra-day markets. Differences between the constraints on generation unit behavior that must be respected in the day-ahead and intra-day markets and constraints respected in the real-time operation of the transmission network are what create the opportunities for suppliers to play the "INC/DEC Game."

\footnotetext{
${ }^{10}$ Operating a power system securely also requires maintaining voltage as well as power flows within operational security limits even after the occurrence of a contingency such as a transmission line or generation unit forced outage. Voltage regulation is a key element for ensuring the security of a power system: too high voltage levels can damage system devices and machinery, while too low voltage levels can lead to voltage collapse causing local or system-wide blackouts. In both cases, voltages out of the range lead to a degradation of the service quality parameters. Low voltage levels are typically experienced during peak hours when a significant amount of reactive power is absorbed by electrical loads and/or when flows on the network are high. Note that when the flow on a line is higher than a given threshold it acts as a reactance, requiring reactive power from the system. High voltages are experienced during low load hours when less reactive power is absorbed by electrical loads and/or when flows on the network are low when the flow on a line is lower than a given threshold it acts as a capacitor, creating an excess of reactive power in the system.
} 


\section{The INC/DEC Game}

We start with a simple characterization of the INC/DEC strategy. Assume, there are two sequential markets, called the day-ahead market and the re-dispatch market. Let us further assume that the re-dispatch market-clearing engine is a richer model compared to the dayahead market-clearing engine as the former accounts for the constraints described in the previous section. The purpose of the re-dispatch market is not only to match supply and demand, but also to ensure secure real-time operation of the power grid. Assume further that market participants are able to predict with some degree of confidence what reliability constraints must be satisfied in real-time. For example, a thermal unit at a particular location may be able to use the past history of system conditions to predict those conditions that make it likely to be indispensable to reliable operation of the grid. The reason that it must operate at a specific level of output or must not operate could be because of transmission congestion, a grid stability issue, or some other system security constraint. From the market participant's perspective, the reason does not matter, only that the unit owner can predict that more or less energy is needed from this generation unit or if a system security constraint is violated.

If the unit owner knows that this unit is necessary in real-time and it can earn a higher price in the re-dispatch market, then the supplier will opt to withhold the unit's capacity from the day-ahead market by submitting a high offer price in the day-ahead market. Under a market-based re-dispatch process, the unit owner will receive their offer price in the redispatch market for the incremental energy sold.

A system security constraint can also make the real-time demand for energy from a particular generation unit zero. Under certain system conditions, even if a unit is offered into the day-ahead market at its marginal cost and receives a positive energy schedule there

are system security reasons why this unit cannot operate in real-time. If such events are predictable, a generation unit will find it profitable to offer such a unit to the day-ahead market and benefit from the fact that its day-ahead schedules will be decreased in the re- 
dispatch market. The owner may even offer into the day-ahead market below the unit's marginal cost because the unit owner knows that the unit will not actually operate in realtime. Under a market-based re-dispatch market, the unit owner can sell back the energy at its offer price and earn the difference between the day-ahead market clearing price and its offer price times the amount of energy purchased in the re-dispatch market.

The energy balance constraint that equates supply and demand at every instance of time for all locations in the grid is the reason why INC/DEC activity has to be examined jointly. If a generation unit at a particular location is required to operate in real-time, but did not sell any output in the day-ahead market, output from some other eligible supply resources has to be DECed in order to make room for the required energy from that unit.

For bid-based day-ahead and re-dispatch markets, the realized variable profit of generation unit $i$ for a particular hour is:

$$
\begin{aligned}
& \pi_{i}\left(\left(b_{i}^{\mathrm{DA}}, g_{i}^{\mathrm{DA}}\right),\left(b_{i}^{\mathrm{RD}}, g_{i}^{\mathrm{RD}}\right)\right) \\
& \quad=p^{\mathrm{DA}} q_{i}^{\mathrm{DA}}+b_{i}^{\mathrm{INC}} \max \left\{0,\left(q_{i}-q_{i}^{\mathrm{DA}}\right)\right\}-b_{i}^{\mathrm{DEC}} \max \left\{0,\left(q_{i}^{\mathrm{DA}}-q_{i}\right)\right\}-C_{i}\left(q_{i}\right) .
\end{aligned}
$$

The unit's realized profit $\pi_{i}$ is a function of the supplier's day-ahead (DA) market offer curve $\left(b_{i}^{\mathrm{DA}}, g_{i}^{\mathrm{DA}}\right)$ as well as the supplier's re-dispatch $(\mathrm{RD})$ market offer curve $\left(b_{i}^{\mathrm{RD}}, g_{i}^{\mathrm{RD}}\right)$, where $b_{i}^{J}$ is the vector of offer prices and $g_{i}^{J}$ the corresponding vector of increment offer quantities for market $J=\{\mathrm{DA}, \mathrm{RD}\}$. Note that the unit's offer curves for the re-dispatch market consist of an INC and a DEC part. The unit's day-ahead schedule is equal to $q_{i}^{\mathrm{DA}}$ and day-ahead market-clearing price is $p^{\mathrm{DA}}$. The unit's real-time output is $q_{i}$ and $C_{i}\left(q_{i}\right)$ the variable cost of producing this output.

The realized profit function of a unit is the sum of four terms. The revenue from the day-ahead market, $p^{\mathrm{DA}} q_{i}^{\mathrm{DA}}$. The revenue from INCing the day-ahead market schedule, $b_{i}^{\mathrm{INC}}{ }^{*} \max \left\{0,\left(q_{i}-q_{i}^{\mathrm{DA}}\right)\right\}$. Because the re-dispatch market is pay-as-offered, the price paid is equal to the offer price associated with the unit's level of production. The third term is the payment for DECing the unit's day-ahead schedule. Again, because the re-dispatch 
market is pay-as-offered, $b_{i}^{\mathrm{DEC}^{*}}$ is the offer price at the unit's final output level. The fourth term is the unit's cost of producing the final output. This equation illustrates the substantial profit opportunities available to generation unit owners that are able to predict when their units will be INCed or DECed in a market-based re-dispatch market.

It is important to emphasize that virtually all fixed-price forward contracts between retailers and generation unit owners in Europe clear against the day-ahead prices using day-ahead energy schedules. Consequently, the fact that generation unit owners have fixedprice forward contract obligations does not eliminate their ability or incentive to play the INC/DEC Game. For example, a generation unit owner could schedule their fixed-price forward contract quantity in the day-ahead market, and then sell either incremental energy or sell decremental energy in the re-dispatch market at their offer price.

We will show that the likelihood of getting INCed or DECed in real-time is predictable at the unit level using only exogenous factors known before suppliers submit their offers to the day-ahead market. These factors include forecasted load levels and forecasted production from intermittent renewable sources. In a second stage, we show that the markup - the difference between a unit's offer price and its marginal cost of producing energy — a generation unit owner submits to the day-ahead market can be explained by the predicted probability of getting INCed or DECed in the re-dispatch market. Specifically, a higher probability of being INCed predicts a higher markup and a higher probability of being DECed predicts a lower markup.

To summarize, withholding capacity from the day-ahead market or overselling capacity in the day-ahead market only makes sense if the likelihood of what will happen in the re-dispatch market is predictable, and that the INC [DEC] price in the real-time market is significantly higher [lower] than the day-ahead market price. In Figure 3, we show the spreads between the average hourly day-ahead market price and the average hourly median paid as-offered prices for INCs and DECs in 2018. ${ }^{11}$ Panel (a) of Figure 3 shows the situation in the Northern

\footnotetext{
${ }^{11}$ The average hourly median paid as-offered price is computed as follows. For each day and hour during the sample period find the median accepted offer price and then compute the mean of these median accepted
} 
bidding zone. Incremental energy sold in the re-dispatch market receives on average about double the price than energy sold in the day-ahead market. Market participants receive on average about half less than the day-ahead price for decremental energy. ${ }^{12}$ The situation is even more extreme in the Center-South bidding zone, especially in the early morning hours, where the average price paid for incremental energy is about five times more than the average day-ahead price and average prices for decremental energy are about a fifth of the average day-ahead price.

The large spreads between the average prices paid for INCs and the day-ahead price and the day-ahead price and the price received for DECs imply a strong incentive to withhold capacity from the day-ahead market and supply to the real-time market or to sell in the day-ahead market and to buy back in real-time. Because of the difference in the operating constraints imposed in the two markets, the day-ahead market is effectively only about matching zonal supply and demand, and the re-dispatch market is about finding the least cost way to operate the grid in real-time given the energy schedules that emerged from the day-ahead market. Competition to supply these incremental and decremental real-time energy needs depends on the capacity and flexibility of the grid, the location and operating level of the generation mix, and the location and temporal net demand pattern. Meeting these transmission network node-level real-time energy needs is subject to significantly less competition than selling energy in the day-ahead market. This fact implies that firms may find it profitable to offer their units in the day-ahead market in such a way that the expected re-dispatch cost is maximized rather than minimized.

Figure 4, Panel (a), shows a day-ahead market offer curve as well as a re-dispatch market offer curve for hour three of April 15, 2018 of a unit that is INCed frequently. ${ }^{13}$ The unit's capacity is offered to the day-ahead market and also to the re-dispatch market at an offer price that is about three times higher than its short-run marginal cost (MC). In Panel (b), offer prices across all days in the sample.

${ }^{12}$ The re-dispatch market pays as offered and we compared the median values with the load weighted average day-ahead market price.

${ }^{13}$ For confidentiality reasons, we do not reveal the names of the units in this paper. 
we show the day-ahead schedule for that day as well as the final schedule. Given the high markup, the unit is not scheduled in the day-ahead market, but it is selected to be INCed in the re-dispatch market.

Figure 5, Panel (a), shows the offer curves of a unit that is frequently DECed for the same day and hour. In the day-ahead market a substantial portion of the unit's capacity is offered at a zero price and the remaining capacity at an offer price below MC. The capacity offered at zero is not a self-schedule but a market offer. In the re-dispatch market, the unit offers to increase its schedule applying a markup of about $80 \%$ of its MC. The unit offered also to decrease its schedule paying back only $0.01 \mathrm{EUR} / \mathrm{MWh}{ }^{14}$ The figure in Panel (b) shows the resulting schedules after each market clearing. During the night, the final schedule will be DECed and the unit earns a profit on the spread between the day-ahead market price and the one euro cent it has offered to pay back for decreasing its schedule.

The day-ahead market price effect of INC/DEC strategies depend on whether the units are infra-marginal or extra-marginal. In the example discussed above, the DEC part of the game is likely to affect the day-ahead market price. At first sight this may be beneficial to the final consumer as day-ahead prices may be lower than MC of the marginal unit but the down-side is that the cost of the re-dispatch will still ultimately show up on the electricity bill of consumers. We discuss this point more thoroughly in Section 7 .

\section{Sample Selection and Data Preparation}

This section first describes the set of generation units that can potentially participate in the re-dispatch market. Although the day-ahead market or intra-day markets are open to all generation units, only a subset of the generation units are eligible to provide INC or DEC re-dispatch energy to ensure secure real-time system operation. These units must satisfy certain technical requirements related to how rapidly they can turn on or off and how fast

\footnotetext{
${ }^{14}$ Note that the zero point for the re-dispatch offer curve is the unit's schedule as of the start of the re-dispatch process
} 
they can increase or decrease their output. ${ }^{15}$ From the set of eligible units, we exclude units that have a cost-of-service contract with the transmission system operator in Italy because they have been shown to have a significant ability to exercise unilateral market power. Units with such contracts have regulatory restrictions on how they can offer their capacity in the day-ahead market. Therefore it does not make sense to include these units in a study of the strategic interaction between the day-ahead market and the re-dispatch market. We also exclude open cycle gas turbines (OCGTs) because they are hardly ever scheduled after the day-ahead market-clearing under the current market environment. The fact that OCGTs are very flexible thermal units with the highest variable cost but low start-up cost compared to other thermal units, makes them suitable candidates for real-time balancing. In absolute terms, OCGTs capacity amounts only to less than $4 \%$ of the total eligible capacity for real-time re-dispatching.

The vast majority of the remaining units are combined cycle gas turbines (CCGTs) and only a handful are coal power plants. The latter are much more "lumpy" compared to the former and therefore we also exclude these units as their lumpiness limits their room for maneuver in real-time. From the remaining units, we select the units that cumulatively provide about $90 \%$ of the total volume of incremental and decremental energy in the scheduling phase of the re-dispatch market. This ensures that only units with a significant share in providing INC or DEC action are analyzed. In total, we selected 40 combined cycle gas turbines (CCGTs) for INC and 32 CCGTs for DEC. These were the main units providing a significant share of INC and DEC energy in the re-dispatch market in 2017 and 2018. Many units are active in both categories and the total number of units in our sample is 61 with a total installed capacity of about $30 \mathrm{GW}$. Given that the hourly average national demand in Italy was about 35 GWh in the years 2017 and 2018 this is a sizeable amount of capacity.

Recall that the main reason a generation unit may opt to under-schedule or over-schedule in the day-ahead market is that a predictable but relevant real-time constraint is not ac-

\footnotetext{
${ }^{15}$ European transmission system operators are currently working to relax the requirements for participation in an effort reduce the rate of increase in re-dispatch costs.
} 
counted for in the day-ahead market clearing engine. Consider, for example, the existence of an important transmission constraint that is ignored in the day-ahead market design but happens to be binding frequently in real-time. Such a situation may incentivize market participants that are affected by this constraint to either over-schedule or under-schedule the output of a unit in the day-ahead market to force the system operator to re-dispatch. Consider for example a stylized system with two nodes and a transmission line that is frequently congested from the North to the South. If the day-ahead market ignores the transmission constraint, units located in the North would have an incentive to over-schedule and units in the South to under-schedule. In real-time, the transmission operator would have to INC the units in the South and to DEC the units in the North to resolve the congestion. This explains why different units can be either INCed or DECed. However, the relevance of transmission network constraints or any other binding security constraints may depend on the season of the year or the hour of the day which explains the overlap in the categories. To summarize, not all units have the same likelihood of being accepted in the re-dispatch market. Their location as well as other attributes such as their ability to ramp-up or down and the state of the system will determine whether a unit is likely to be INCed or DECed. However, in order to demonstrate that we have not selected the generation units for our analysis to produce the desired outcome, we also provide the results of the analysis using all CCGT units that are eligible to provide energy in the re-dispatch market (see Section A).

We focus on the interaction between the day-ahead market and the scheduling phase of the re-dispatch market. In Figure 6, we see that, on average, more than half of the INC action and about half of the DEC action is already selected in the scheduling phase of the re-dispatch market. The reason why we focus on the scheduling phase is that the sizeable re-dispatch actions typically take place in the scheduling phase and not in the realtime balance market sessions. However, we provide the results where we also include the real-time balancing market outcomes as a robustness check in Section 6 .

In order to simplify the analysis, we ignore transactions in the intra-day markets as 
unlike in Ito and Reguant (2016), we do not observe large price spreads between day-ahead market and intra-day markets on average. Furthermore, trading volume is very low in the intra-day markets. ${ }^{16}$ In principle, trading possibilities in the intra-day markets may even aggravate the INC/DEC gaming problem as market-participants have several opportunities to schedule their capacity and may use the resulting price and schedules of their own units in the previous market sessions as signal to learn about the state of the system. In that sense our results will be a lower bound on how the expected probability of being re-dispatched will affect the day-ahead market offer markup.

Our final data-set combines hourly unit-level offer data from the day-ahead market as well as the re-dispatch market. The day-ahead offer data is condensed into unit-level day-ahead market offer price markups described in more detail below. ${ }^{17}$

\subsection{Predicting the likelihood of getting INCed or DECed}

We now describe the statistical model used to predict the probability that a generation unit is INCed or DECed in the re-dispatch market. We are interested in the interaction between the day-ahead market and the re-dispatch market and how the expected probability of getting INCed or DECed in this market affects day-ahead market offer-price markups. Our model must predict the likelihood of getting INCed or DECed in the re-dispatch market using information available to generation unit owners before they submit their offers to supply energy in the day-ahead market.

We use the following exogenous variables that are all known before suppliers submit their offers to the day-ahead market: national zonal day-ahead forecasts for load, wind, and solar energy. Forecasts for the same set of variables for the neighboring countries, i.e.,

\footnotetext{
${ }^{16}$ For the year 2018, the average price in the northern bidding zone - the largest zone in Italy - was 60.7 EUR/MWh in the day-ahead market and $60.3 \mathrm{EUR} / \mathrm{MWh}$ in the first intra-day market session. The first intra-day market session is also the most important one in terms of transactions relative to the other intra-day market sessions. Average hourly national purchases amounted to $1.3 \mathrm{GWh}$ in the first session of the intra-day market compared to $34 \mathrm{GWh}$ in the day-ahead market.

${ }^{17}$ We omit observations for hours where a unit's available capacity is below $20 \%$ of its installed capacity. For such low levels of available capacity our short-run marginal cost estimate is likely to be off. However, our results are not sensitive to this small modification of the original data.
} 
Austria, France, Greece, Slovenia, and Switzerland. We also include these same variables for Germany because Europe has a common zonal day-ahead market of electricity and Germany with its large share of intermittent renewables, plays an important role. We also include the day-ahead market cross-border transmission limits with all adjacent countries and the national zonal transmission limits for Italy. ${ }^{18}$ Finally, we use month-of-year, hour-of-day, and workday indicator variables. ${ }^{19}$ The values of these exogenous variables are collected to form the regressor matrix $X$.

We code the dependent variable $y$ to be equal to one if a unit's schedule is INCed [DECed] and zero otherwise. We separately estimate the parameter vector $\beta$ for each unit and for each re-dispatch market product, i.e., for INC and DEC energy separately, imposing a model of the form

$$
\mathbb{P}[y=1 \mid X]=F(X \beta) .
$$

The function $F(t)$ in (2) can be replaced by the logistic cumulative distribution function and the model then becomes the standard binary logit model. We apply a logit model to estimate the probability of getting INCed or DECed. We also use a machine-learning technique to estimate these probabilities. In particular, we apply a cross-validated random forest classification model. ${ }^{20} \mathrm{~A}$ serious concern in all machine-learning algorithms is over-

\footnotetext{
${ }^{18}$ Data on hourly day-ahead load forecasts as well as hourly day-ahead forecasts for solar and wind at the bidding zone level is publicly available from https://transparency.entsoe.eu/. "According to Regulation Article 6.1.b and 6.2.b, a day-ahead forecast of the total load per market time unit; ... shall be published no later than two hours before the gate closure of the day-ahead market in the bidding zone and be updated when significant changes occur;" Day-ahead forecasts for wind and solar shall be published no later than $6 \mathrm{pm}$ Brussels time one day before actual delivery takes place. The day-ahead market session closes at noon and therefore the wind and solar day-ahead forecast is provided a few hours after the closure of the dayahead market. However, forecast data for wind and solar is a standard product that can easily be procured by market-participants. Furthermore, it can be expected that the solar and wind day-ahead forecast at noon should be highly correlated with the day-ahead forecast published by the transmission operator a few hours later. Nevertheless, we replicate the analysis using a simplified forecast model where we exclude the day-ahead forecasts of wind and solar. The results are presented in Table 11. The qualitative interpretation of the results is unchanged. Data on zonal transmission limits is provided to Italian market-participants by the transmission system operator before the day-ahead market closes.

${ }^{19}$ Workdays are all non-holidays and non-weekend days.

${ }^{20} \mathrm{Put}$ simply, a random forest model consists of a large number of individual decision trees that operate as an ensemble. Each decision tree model in the forest produces a class prediction and the mode of all the classes, i.e., the most frequent outcome, becomes the model's prediction. We use a standard parameter setting for the random forest classification model and did not optimize hyper-parameters. We also experimented with other
} 
fitting. For this reason, we apply a cross-validation strategy using $20 \%$ of the sample as test data and the remainder as training data. We use five stratified randomized splits that preserve the same percentage for each target class as in the complete set.

In Table 1, we benchmark the outcome of the two prediction models and summarize their accuracy, precision, and recall values. To compute these model performance magnitudes, we assume the predicted value of $y, \hat{y}$, is equal to one it the predicted $\mathbb{P}[y=1 \mid X]>0.5$ and zero otherwise. The "Accuracy" metric measures how often the classifier is correct, i.e., summing up the true positives and the true negatives and dividing by the sample size. The "Precision" metric is how often the positive predicted values are correct, i.e., the number of true positives divided by the sum of the number of true positives and the number of false positives. The "Recall" or "Sensitivity" metric is the true positive rate, that is the number of correctly identified positives divided by the total number of actual positives. We calculate each metric at the unit level, and the table displays the mean and standard deviation across all units. Columns (1)-(2) summarizes the accuracy metrics for the models that predict the probability of getting INCed while Columns (3)-(4) summarizes accuracy of the DEC prediction models. Columns (1) and (3) correspond to the logit model, Columns (2) and (4) correspond to the cross-validated random forest model. The random forest model outperforms the logit model across all measures for INC as well as for DEC, that is why we select it as our preferred model for the probability a generation unit is INCed or DECed.

\subsection{Calculating day-ahead offer markups}

This section describes how generation unit level markups, defined as the difference between the day-ahead market offer price and the short-run marginal cost for a generation unit, move with probability a generation unit is INCed or DECed. Each unit can be offered into the day-ahead market with a weakly increasing step function offer curve with four price steps.

machine-learning algorithms, e.g., a cross-validated logistic regression model with $l^{2}$-norm regularization. However, the cross-validated random forest classification model outperformed all other models based on the criteria given in Table 1. 
Table 1: Summary of Prediction Models

\begin{tabular}{lrrrrr}
\hline & \multicolumn{2}{c}{ INC } & & \multicolumn{2}{c}{ DEC } \\
\cline { 2 - 3 } \cline { 5 - 6 } & \multicolumn{1}{c}{$(1)$} & $(2)$ & & $(3)$ & \multicolumn{1}{c}{$(4)$} \\
\hline Accuracy & 0.89 & 0.94 & & 0.82 & 0.89 \\
& $(0.06)$ & $(0.03)$ & & $(0.07)$ & $(0.03)$ \\
Precision & 0.68 & 0.98 & & 0.66 & 0.93 \\
& $(0.08)$ & $(0.03)$ & & $(0.07)$ & $(0.07)$ \\
Recall & 0.29 & 0.50 & & 0.38 & 0.53 \\
& $(0.18)$ & $(0.17)$ & & $(0.23)$ & $(0.25)$ \\
\hline
\end{tabular}

Notes: Table displays mean and standard deviation (in parentheses) of unit-level predictions to be INCed or DECed across all units. Results in Columns (1) and (3) correspond to a logit model and Columns (2) and (4) correspond to a cross-validated random forest model.

We calculate an offer-quantity-weighed average offer price for each hour and unit. Reducing the offer curve to a single number makes it easy to compare it to the short-run marginal cost. We calculate the short-run marginal cost for each unit and day based on heat-rate estimates, daily market quotations of fuel costs, variable operation and maintenance costs, and monthly average emissions prices (see Graf et al., 2020, for more details). Subtracting the marginal cost from the quantity weighed average offer price results in the markup. We use all day-ahead market price offers (including self-schedules).

For the case that capacity from a generation unit was not offered in the day-ahead market we assign an offer price of $300 \mathrm{EUR} / \mathrm{MWh}$ to the available capacity. Participation in the dayahead market is not compulsory and therefore market participants may opt to withhold (part of) their capacity by either not offering it at all or offering it at a very large offer price. The maximum observed price for the demand side in the day-ahead market was $170 \mathrm{EUR} / \mathrm{MWh}$ over the years 2017 and 2018. Hence, setting the offer price as high as 300 EUR/MWh has the same effect as a physical capacity withholding. In Section 6, we provide the results of a robustness check that does not depend on the assumption of employing a fictitious offer price for physically withheld capacity. 


\section{$5 \quad$ Empirical Results}

In this section, we show that there is a precisely estimated increasing relationship between the predicted probability of getting INCed in the re-dispatch market and the markup set in the day-ahead market and decreasing relationship between the predicted probability of getting DECed in the re-dispatch market and the markup set in the day-ahead market.

Before we estimate the predicted probability of getting INCed or DECed in the redispatch market and the markup set in the day-ahead market using all the units in our sample and different sets of controls, we present a graphical analysis using the binscatter developed in Cattaneo et al. (2019). We control for generation unit-level, hour-of-day, dayof-week, and month-of-year fixed effects and choose the number of selected bins to minimize the (asymptotic) integrated-mean-squared error as recommended in Cattaneo et al. (2019). Figure 7, Panel a, shows an approximate upward sloping linear relationship between the predicted probability of getting INCed and the markup set in the day-ahead market. In Panel b, we find the opposite relationship, i.e., an approximate downward sloping linear relationship between the predicted probability of getting DECed and the markup set in the day-ahead market.

In estimating the relationship between the predicted probability of getting INCed or DECed in the re-dispatch market and the markup set in the day-ahead market we include generation unit level fixed effects that account for the fact that different generation units set different baseline markups. We summarize these results in Table 2. Columns (1), (2), (3), and (4) show the regression results for the units that supply most of the incremental energy and Columns (5), (6), (7), and (8) for the units providing most of the decremental energy. In Columns (1) and (5), we use a very basic panel data regression specification accounting

only for unit fixed effects. In the model specification displayed in Columns (2) and (6), we account also for hour of the day fixed effects as well as month of the sample fixed effects.

The results of a more flexible model formulation accounting also for the interaction effects between unit and month of the sample is presented in Columns (3) and (7). Finally, in 
Columns (4) and (8), we include cubic polynomials of the forecast net load that is the dayahead load forecast net of the forecast supply from wind and solar, hour-of-day, day-of-week, and month-of-year fixed effects.

The coefficient of interest in all these regressions is on the predicted probability of getting INCed or DECed. The interpretation of this coefficient is that if the predicted probability of getting INCed [DECed] increases from zero to one the markup increases [decreases] by $x$ EUR/MWh. In Panel A - the specification where we include all observations, the coefficient of the predicted probability of getting INCed [DECed] ranges between 79 and 103 EUR/MWh [-161 and $-149 \mathrm{EUR} / \mathrm{MWh}$. The standard errors are clustered at the unit level to allow for arbitrary forms of autocorrelation and heteroscedasticity in the errors across generation units. Even with these standard errors the parameter estimates are very precisely estimated, confirming that when the predicted probability of getting INCed is high a large markup is set in the day-ahead market. In the DEC case, we observe the opposite effect; when the predicted probability of getting DECed increases the markup on the day-ahead market offer price decreases. As mentioned previously, even a negative markup may be a profitable strategy in case of a high probability of getting DECed in the re-dispatch market and given a spread between the day-ahead market price and the DEC price that is positive.

A potential concern with our analysis may be that we also include market bids that have only a slim chance of being dispatched at all and hence underestimate the effect of the predicted probability of being INCed or DECed on the markup put on the day-ahead market offers. Italy has a substantial amount of CCGT capacity that operates with low capacity factors. ${ }^{21}$ Consequently, in some hours there is only very little demand left to be served by these CCGT units. In cases where a unit has a small chance of being dispatched at all or only for a few hours it may be rational to bid a steep offer curve into the day-ahead market. This behavior is enforced by the different market-clearing models. If a unit will be dispatched

\footnotetext{
${ }^{21}$ Reasons for that are: (i) cheap imports from neighboring countries (nuclear in France and hydro in Switzerland and Austria), (ii) cheap domestic production from hydro (Italian alps) and renewables (wind, solar, and geothermal).
} 
in the re-dispatch market it will also be compensated for its energy as well as its offered start-up cost. This makes offering capacity in the day-ahead market riskier than selling into the re-dispatch market, because the day-ahead market provides the unit with no guarantee that it will recover its start-up costs. To show that this concern has a tangible impact of our empirical results, we exclude all offers that are not dispatched in the day-ahead market or in the re-dispatch market. The results of this exercise are summarized in Table 2, Panel B. For the INC side we find that of the 612,939 total observations only 331,563 remain, when applying our criteria. Comparing the estimates of the intercept for the base-line model using all observations (Panel A, Columns 1 and 5) with the estimates of the reduced sample (Panel B, Columns 1 and 5), we find that the estimated intercept becomes effectively zero. ${ }^{22}$ That means, the predicted markup of the average unit is zero when the predicted probability of getting INCed or DECed is zero. Put differently, the average unit is offered competitively to the day-ahead market in case there is no predictable outside option when we restrict the sample to only market-relevant transactions. As a consequence, we find that the coefficient of interest increases by approximately factor two on the INC side. Accounting also for the change in the intercept, the average predicted markup if the predicted probability of getting INCed equals one, is about $222 \mathrm{EUR} / \mathrm{MWh}$ compared to $164 \mathrm{EUR} / \mathrm{MWh}$ when we do not restrict the sample. This shows that for bids that are market-relevant the average markup moves even more strongly with an increase in the expected probability of getting INCed. On the DEC side, the coefficients on the predicted probability of getting DECed is approximately halved. The qualitative interpretation of our results is unchanged as a result of this sample selection procedure. A high predicted probability of getting INCed predicts an higher markup in the day-ahead market and a higher predicted probability of getting DECed predicts a lower markup.

In order to demonstrate that these results can also be derived by using conventional pre-

\footnotetext{
${ }^{22}$ The intercept is calculated in line with the logic of how it is implemented in Stata and therefore represents the average value of the fixed effects, see https://www.stata.com/support/faqs/statistics/ intercept-in-fixed-effects-model/ for more details.
} 
diction models such as a logit model or a linear probability model to estimate the probability of getting INCed or DECed at the unit level, we re-run the analysis described above with the only difference that a different prediction model is used. The results are summarized in Table 3 and besides having slightly smaller in absolute value coefficients of interest, our qualitative results are unchanged.

The previous model uses the estimated probability of being INCed or DECed to explain the day-ahead market offer markup. A different modeling approach would be to make the assumptiong that generation unit owners have rational expectations about when their units will be INCed or DECed and these expectations on variables we use to estimate the probability of being INCed or DECed. This assumption replaces the probability of the unit being INCed or DECed with the indicator variable of whether a unit was INCed or DECed and uses the predicted probability as an instrument for this endogenous indicator variable. In Table 4, we present the results separately for all three models to derive the unit-level predictions of getting INCed or DECed. The coefficients are slightly lower for the INC side and slightly larger for the DEC side than in the specifications where we directly use the predicted probability and all of the coefficient estimates are precisely estimated.

\subsection{Double/Debiased Machine Learning Estimate}

In the previous section we accounted for a fairly limited set of controls in estimating our markup models. We replace the set of controls we used with a rich set variables, including zonal residual demands (national and neighbouring countries and Germany), squared terms and interaction terms thereof; transmission limits; gas prices, gas prices squared; unit, hourof-day, workday, and month-of-year fixed effects. Given the large number of regressors, OLS estimation of this model may lead to over-fitting. A naïve approach would be to simply estimate the model using a LASSO regression. The advantage of LASSO is that it will pick the most important regressors from the large set of regrossors potentially including many irrelevant regressors (sparsity assumption). However, in any case the resulting estimates 
will be biased due to the regularization term introduced in LASSO. Therefore, we apply the double/debiased machine learning for treatment effects parameters introduced by Chernozhukov et al. (2018). ${ }^{23}$ We present the results using this approach in Table 5. The point estimates, are almost identical to the estimates when only controlling flexibly for the net load as presented in Table 2, Panel A, (Column 4 for INC and Column 8 for DEC).

\section{Robustness Analyses}

In our main specification for predicting whether a unit will be INCed or DECed in the redispatch market, we ignore portfolio effects between generation units owned by the same market participant. Our main argument for this prediction model is that generation units have unique characteristics such as location or technology that makes them an essential resource for balancing the market and ensuring a secure operation of the grid. However, there may still be portfolio effects in the sense that the likelihood of a unit being taken in the re-dispatch market may also depend on how the firm has offered its portfolio of generation unit into the day-ahead market. As emphasized by Graf and Wolak (2020), the spatial distribution of firm level offer curves can impact the prices paid all generation units owned by the firm.

The first modification of our prediction model is therefore to include the zonal quantity the unit owner has offered to the day-ahead market at "competitive offer prices." More precisely, we calculate the aggregate zonal quantity for each firm that has been offered into the day-ahead market at a price lower or equal to its short-run marginal cost. We only account for thermal units that are eligible to be operated in the re-dispatch market. For each of the INC and DEC units under consideration, we then add only the quantity values of the same firm, say firm $X$ owns unit $j$ that is a relevant INC unit; then we add only the capacity offered competitively by firm $X$ as explanatory variable. Adding this feature to the

\footnotetext{
${ }^{23}$ We use Stata's implementation, that is, the cross-fit partialing-out lasso linear regression (xporegress). We use the standard parametrization, most importantly, ten folds for cross-fitting.
} 
probability of an INC or DEC in the re-dispatch market model improves our forecast metrics (see Table 6, Panel A). Regressing the day-ahead markup using the alternative prediction of an INC or DEC in the re-dispatch market only slightly changes the relevant coefficients though (see Table 7, Columns 1 and 4).

The second robustness check we consider is that instead of using only data from the scheduling phase of the re-dispatch market as our measure of the unit-level re-dispatch INC and DEC demand, we replace it by the total re-dispatch demand for INCs and DECs from the unit. That is the sum of the INC and DEC demand for each unit from the scheduling phase of the re-dispatch market and the real-time balancing market. Only sizeable INCs and DECs, with at least $10 \%$ of the unit's available capacity are counted as INCs and DECs for this analysis. The reason for this definition of INCs and DECs is that in practice a unit may be INCed and DECed several times between the day-ahead market-clearing and real-time depending on the several updates of the state of the system. For example a unit may be INCed by $20 \%$ of its available capacity in the scheduling phase of the re-dispatch market and the same unit may be DECed by $1 \%$ of its capacity to balance the system in real-time. Strictly speaking this unit would not only be INCed in the real-time re-dispatch market but would also be DECed. In order to better filter out the dominant part of the unit-level real-time demand for INC and DEC we apply the 10\% criterion. The prediction metrics for this definition of generation unit-level INCs and DECs are presented in Table 6, Panel B, and the regression of the markups on predicted probabilities of an INC and DEC are given in Table 7, Columns (2) and (5). Our qualitative results are not impacted by this modified definition of INCs and DECs.

In Table 6, Panel C, and Table 7, Columns (3) and (6), we present the INC and DEC prediction metrics as well as the markup regression results combining both alternative specifications described above. Specifically, we use the $10 \%$ of capacity criteria for INCs and DECs described above and then we account for the portfolio effects described in the second paragraph of this section in the INC and DEC prediction model. Once again, we find 
that our empirical results for the impact of an increase in the probability of being INCed or DECed on offer price markups in the day-ahead market are qualitatively similar to the results in the previous section.

Another concern may be that we are using the markup set in the day-ahead market. Market participants are allowed to submit non-decreasing step functions with four steps for each unit into the day-ahead market, hence the unit-level markup is a function of the offered quantity. We by-pass this challenge by calculating a capacity-weighted average offer price where we have associated a $300 \mathrm{EUR} / \mathrm{MWh}$ offer price to available capacity that is not offered in the day-ahead market. In order to show that our results are independent of both assumptions, we construct an alternative metric, that is the competitivly offered capacity share. This share is calculated as the quantity offered to the day-ahead market at an offer price lower or equal than the unit's short-run marginal cost relative to its available capacity. If the firm offers all its capacity at short-run marginal cost or below this metric takes the number one. If all the capacity is withhold from the day-ahead market or offered above the unit's short-run marginal cost this metric takes the number zero. For piece-wise constant offer functions that intersect with the short-run marginal cost of the unit, the metric takes a number between zero and one.

The regression results are presented in Table (8). Note that the signs of the coefficients are reversed now, which is due to the construction of the metric. For example a negative share of competitively offers capacity $x$ for the INC re-dispatch product means that if the probability of getting INCed increases from zero to one, the unit's owner offered $x$ percent less of its available capacity than when the probability of getting INCed is zero. In other words, as the probability of getting INCed increases less capacity will be offered competitively into the day-ahead market. We find the reverse effect for the DEC re-dispatch product. To summarize, the results using the competitive offer share at the unit-level instead of the markup yields effectively the same quantitative results as our markup results. 


\section{Total Cost to Serve Load and Re-dispatch Cost}

This section explores the market efficiency consequences of INC/DEC activity documented in the previous section. A fully fletched competitive benchmark, where a security constrained unit commitment optimization problem using each unit's short-run marginal cost and competitive start-up cost is run, is presented in a companion paper (see Graf et al., 2020). A first glimpse at this cost can be inferred from Figure 3 which shows a large distance between median awarded INC and DEC prices in the re-dispatch market and average day-ahead market prices. In this section, we provide further evidence on how the net demand, the system demand less intermittent renewables production, affects day-ahead market prices and re-dispatch costs.

The actual hourly real-time re-dispatch cost are

$$
\sum_{j} p_{j}^{\mathrm{INC}} q_{j}^{\mathrm{INC}}-p_{j}^{\mathrm{DEC}} q_{j}^{\mathrm{DEC}}
$$

where $p_{j}^{\mathrm{INC}}$ is the INC price paid to unit $j, q_{j}^{\mathrm{INC}}$ is the INC quantity sold by unit $j, p_{j}^{\mathrm{DEC}}$ is the DEC price paid by unit $j$ and $q_{j}^{\mathrm{DEC}}$ is the DEC quantity purchased by unit $j$. This is the actual cost of the re-dispatch the transmission system operator passes through to the final consumer in form of the grid fee. We compute total re-dispatch costs and the cost of real-time demand at the hourly day-ahead price for all hours of two-year sample period. Total re-dispatch costs are $9 \%$ of this measure of the total cost of real-time demand over our two-year sample period. ${ }^{24}$

However, the re-dispatch cost calculated above does not include the economic value of energy sold in the day-ahead market that is useless in real-time. More precisely, the total DEC quantity that is bought back by the market participants was first sold at the day-ahead

\footnotetext{
${ }^{24}$ The annual total demand (net of pumping and grid losses) reached 303 TWh in 2018 and 302 TWh in 2017. The average day-ahead market price relevant for the demand side was $61.3 \mathrm{EUR} / \mathrm{MWh}$ in 2018 and 54.0 EUR/MWh in 2017. Re-dispatch cost that includes the procurement of reserves as well as real-time balancing was about 1.5 billion Euros per year in 2017 and 2018 (these figures do not include payments for start-up costs and thus represent a lower bound of the actual re-dispatch cost). Thus, re-dispatch cost are $\frac{2 \cdot 1.5 \cdot 1 \mathrm{e} 9}{(303 \cdot 61.3+302 \cdot 54) 1 \mathrm{e} 6} \approx 9 \%$ of the total cost of real-time demand over our two-year sample period.
} 
market price. The following modification accounts for this aspect

$$
\sum_{j}\left(p^{\mathrm{DA}}-p_{j}^{\mathrm{DEC}}\right) q_{j}^{\mathrm{DEC}}+p_{j}^{\mathrm{INC}} q_{j}^{\mathrm{INC}}
$$

where $p^{\mathrm{DA}}$ is the day-ahead price. Using the metric above, we find the total economic cost of the re-dispatch to be $15 \%$ relative to real-time demand valued at the day-ahead market price over our two-year sample period.

Figure 8, Panel (a), shows the daily re-dispatch cost defined in (3) as a function of daily net demand. In the re-dispatch market, intertemporal constraints on thermal resources are accounted for and the optimization horizon of the first session of the re-dispatch market is 24 hours. That is why we focus on daily re-dispatch costs as they also include the cost paid to thermal units for start ups. Surprisingly, the figure reveals a U-shaped relationship between the re-dispatch cost and the net demand. While the right part of the "U" can be explained by traditional market power logic, that a higher demand means that there is less competition for a marginal increase of supply.

The left part of the "U" requires more explanation. On low-demand days such as weekend days, holidays, or days with typical levels of renewable production, one would expect low re-dispatch costs because of substantial competition between thermal plants that have spare capacity. However, on days with low net demand, the transmission grid may be more vulnerable because little controllable capacity is committed and therefore voltage issues may arise. As a consequence, the transmission system operator usually requires a small number of units to be online at different locations to ensure secure operation of the grid. However, if these unit owners are able to predict when these units are needed, they may decide to schedule different units in the day-ahead market and wait to get paid as-offered to increase the output from these necessary units. As shown in Section 3, the units scheduled in the day-ahead market that cannot meet these locational energy requirements will sell back decremental energy at a lower price than the day-ahead market price. Consequently, a supplier that owns multiple generation units could earn revenues from both INCing and DECing in 
the re-dispatch market during the same hour of the day.

In Table 9, we regress the re-dispatch cost on the net demand (Column 1), use the squared net demand (Column 2), and also include the intradaily standard deviation of the net demand (Column 3). We include month-of-sample fixed effects in all regressions to account for monthly variation in hydro production but also in output from renewable sources (primarily solar photovoltaics). We show the average marginal effects evaluated at different net demand levels for the last two regression specifications in Figure 8, Panel (b). The average marginal effects confirm the fitted U-shaped functional form in Figure 8, Panel (a). Put differently, an increase in net demand in low net demand days predicts a reduction of the re-dispatch cost while an increase in high net demand days predicts an increase of the re-dispatch cost.

There is a vast amount of literature showing that an increase of close-to-zero marginal cost renewables leads to lower day-ahead market prices (see e.g., the literature review in Wozabal et al., 2016). All these papers assume a static merit order stack of conventional power plants and an increase in output of infra-marginal renewables acts as if the demand were decreased and therefore makes a cheaper unit marginal. We find this effect in the Italian day-ahead market (see Figure 9, orange line). The relationship appears to be inverse S-shaped which is in line with what Wozabal et al. (2016) found. We then calculate the total cost to serve load that we define as

$$
p^{\mathrm{DA}} Q^{\mathrm{RT}}+\sum_{j} p_{j}^{\mathrm{INC}} q_{j}^{\mathrm{INC}}-p_{j}^{\mathrm{DEC}} q_{j}^{\mathrm{DEC}}
$$

where $Q^{\mathrm{RT}}$ is the actual demand in real-time. The second fitted line in this figure represents this total cost per MWh demand and surprisingly we find that the average total cost seem to be diverging from the day-ahead market price on days with low net demand. The Ushaped re-dispatch cost makes the average cost of serving load significantly more expensive on low net demand days. Note that the INC/DEC activity has exactly this effect because capacity is offered to the day-ahead market at offer prices below short-run marginal cost 
which depresses the day-ahead market price and through INC activity firms earn profits in the re-dispatch market.

\section{Discussion and Conclusion}

We find that the conditional probability of being INCed or DECed in the re-dispatch market will change the day-ahead offer markup set by market participants for their thermal power

plants. In other words, the re-dispatch market provides a lucrative outside option to sell energy because the day-ahead market does not include all the constraints that appear to be relevant for secure real-time operation of the electricity grid. These results from the Italian electricity market are a cautionary tale for the European Commission, which has recommended market-based re-dispatch processes. Unlike in continental European day-ahead market-clearing engines, Italy accounts for within-country transmission constraints through bidding zones. Consequently, re-dispatch costs as a fraction of total wholesale energy costs in Italy are likely to be lower than in the single-zone markets that exist in other European countries.

Without any knowledge of real-time electricity system operation it may be tempting to look at the day-ahead market and the re-dispatch market as sequential markets. In financial economics such markets are seen as connected systems with trade-flows between these markets. To make this point clear, assume two liquid markets that clear shortly after each other with no change in expectation what will happen in real-time that is the point in time were delivery will take place. In such a case one would expect that there would be trade-flows to equalize the market-clearing prices. If the price in one market would be structurally higher than the one in the other market, some player would arbitrage the price difference away. This logic is flawed in simplified electricity markets as the final operating levels of all generation units will also be constrained by the laws of physics, rather than the results of the day-ahead market. In simplified day-ahead market designs that do not account 
for physical constraints, the re-dispatch market operates on a fundamentally different basis than the day-ahead market. Hence, the day-ahead market may be used by strategic players to schedule their capacity to increase their profits through re-dispatch actions.

Independent of whether the re-dispatch market is market-based or cost-regulated, there are a number of additional potential market inefficiencies that appear to be a direct result of the divergence between market operation day-ahead and real-time. In the short-term, efficiency losses due to an sub-optimal level of net-imports in an interconnected European market can be expected. Currently the European day-ahead market-clearing endogenously determines the level of imports. ${ }^{25}$ However, if the day-ahead market result diverges structurally from the real-time market result, the level of net-imports cleared in the day-ahead market is sub-optimal. To make this point clearer, consider the case in which transmission constraints are not accounted for in the day-ahead market. Consequently, prices may be structurally higher in an area with most of the cheap generation capacity, typically renewable capacity, than they would be the case in an locational marginal pricing (LMP) market. In a coupled market, this area will tend to import more capacity from neighboring bidding zones/countries, than the level of imports expected in case of greater locational pricing granularity. The sub-optimal amount of net-imports could potentially further increase the need for re-dispatch actions. European transmission system operators address this problem by implementing advanced capacity calculation methodologies for properly computing trade capacity between European bidding zones using flow-based methodologies. These methodologies attempt to mimic the nodal behaviour of the grid, but they also include sufficient

\footnotetext{
${ }^{25}$ In 2018, the project is being operated by seven Power Exchanges: EPEX SPOT, GME, Nord Pool, OMIE, OPCOM, OTE, and TGE; PCR is used to couple the following countries: Austria, Belgium, Czech Republic, Denmark, Estonia, Finland, France, Germany, Hungary, Italy, Latvia, Lithuania, Luxembourg, the Netherlands, Norway, Poland, Portugal, Romania, Slovakia, Slovenia, Spain, Sweden, and the United Kingdom. See, e.g., https://www. epexspot.com/en/marketcoupling\#price-coupling-of-regions-pcr. This makes it the largest day-ahead market for electricity in the world with about 2.9 TWh of consumption (based on Eurostat data for 2017). To put things into perspective, the largest integrated US market is the Pennsylvania-New Jersey-Maryland interconnection (PJM) serving all or parts of Delaware, Illinois, Indiana, Kentucky, Maryland, Michigan, New Jersey, North Carolina, Ohio, Pennsylvania, Tennessee, Virginia, West Virginia, and the District of Columbia with an annual demand of about 0.8 TWh (https://www.pjm.com/ -/media/about-pjm/newsroom/annual-reports/2017-annual-report.ashx).
} 
reliability margins to coping with uncertainties underlying in managing the system in real time. All these methodologies attempt to fix a problem that would not exist if day-ahead market outcomes where closer to real-time system operation. Furthermore, these calculations are made before the day-ahead market clears and therefore are not suitable to react quickly to changes in bidding strategies of market participants. Moreover, as the Italian experience shows, there might be other relevant security constraints rather than transmission constraints that will determine the final dispatch.

Another concern is the divergence between day-ahead market prices and actual hourly cost to serve load shown in this paper. While hourly day-ahead market prices are used for clearing forward contracts but also for demand side management, they do not reflect the true cost of an additional unit of demand in real time. While the day-ahead market prices are granular with respect to time and optimally also with respect to location, the re-dispatch cost shows up on the monthly bill of a final consumer in form of the grid fee, averaged over time and location. This can lead to inefficient price signals for new investment in demand response, storage, and other load-shifting technologies.

This aspect of the divergence between day-ahead market operation and real-time market operation is also concerning in a wholesale market combined with a regulated re-dispatch process. Consider the following illustrative example take from Germany: Substantial cheap intermittent generation capacity (e.g., renewables) in the North due to favorable weather conditions (e.g., a windy area) paired with significant load in the South and insufficient transmission capacity to transport the low cost, zero-carbon electricity from the North to the South with the consequence that sometimes renewable production must be curtailed. However, since the day-ahead market design is agnostic towards the "physical reality" of how power flows, all the renewable power is sold day-ahead although it will not be possible to deliver it in real-time. Consequently, this will lead to higher prices in the North compared to a market design that acknowledges transmission constraints. Suppose an investor who would like to add renewable capacity to this market. Ignoring subsidies and property prices, 
she would build the additional renewable capacity at a location with the highest correlation of expected temporal output and expected temporal electricity prices, i.e., most likely in the North. Although, this capacity can be sold day-ahead it will be curtailed in real-time in many hours and through the re-dispatch a fossil-fuel plant in the South will have to produce the curtailed energy. Hence, from a consumer perspective as well as from an environmental perspective this investment is inefficient. 
Figure 1: System Demand Less Renewable Energy Production in Germany 2007 to 2018
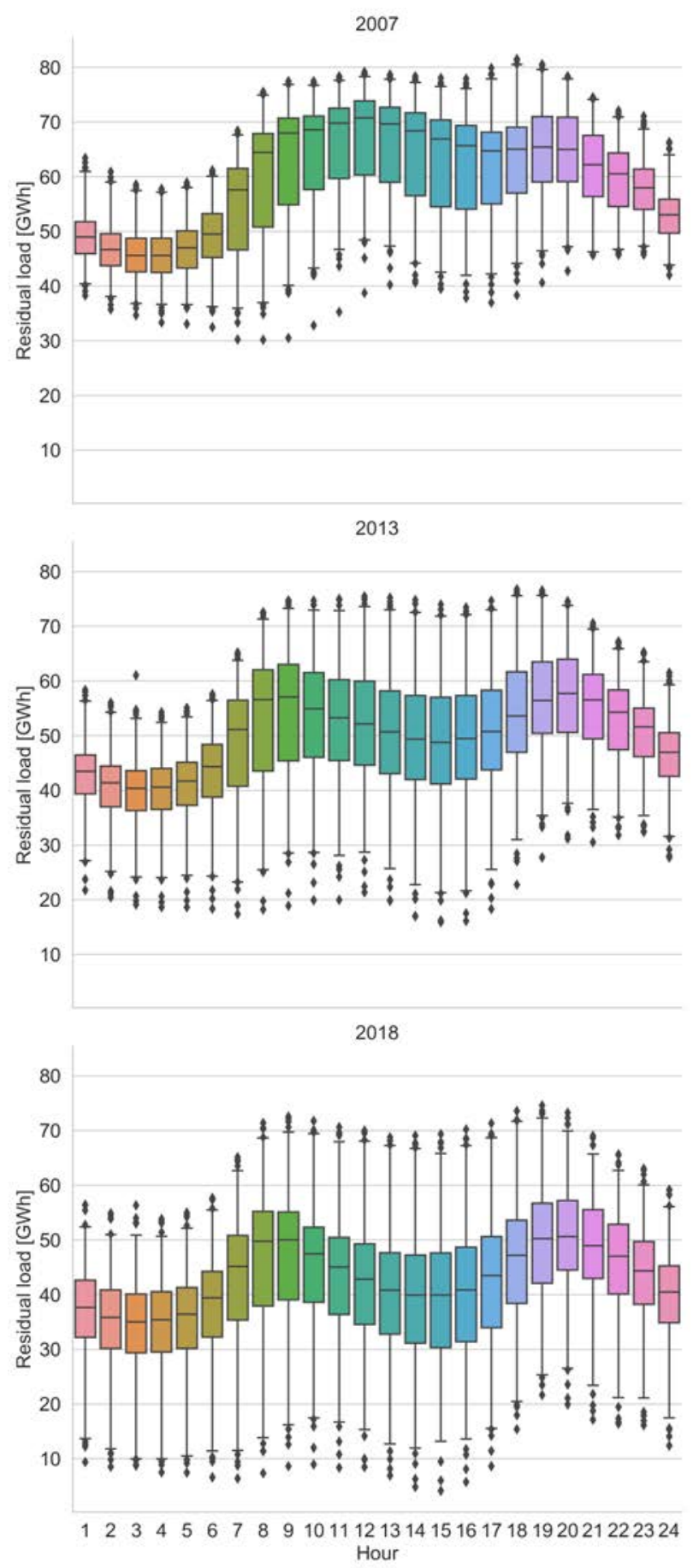

Notes: Hourly net demand in Germany, i.e., the national load minus the supply from wind and solar. Boxes represent interquartile range (IQR) and upper and lower vertical bars equal to the 1 percent and 99 percent. Diamonds represent outliers not included in the 1-99 percentile. Hourly data for load, wind, and solar for the year 2007 are from Entso-e and the four German transmission system operators (see Wozabal et al., 2016, for a more detailed description on the data sources). Data for the years 2013 and 2018 are from Open Power System Data (2019). 
Figure 2: Demand Less Renewable Energy Production in Italy 2007 to 2018
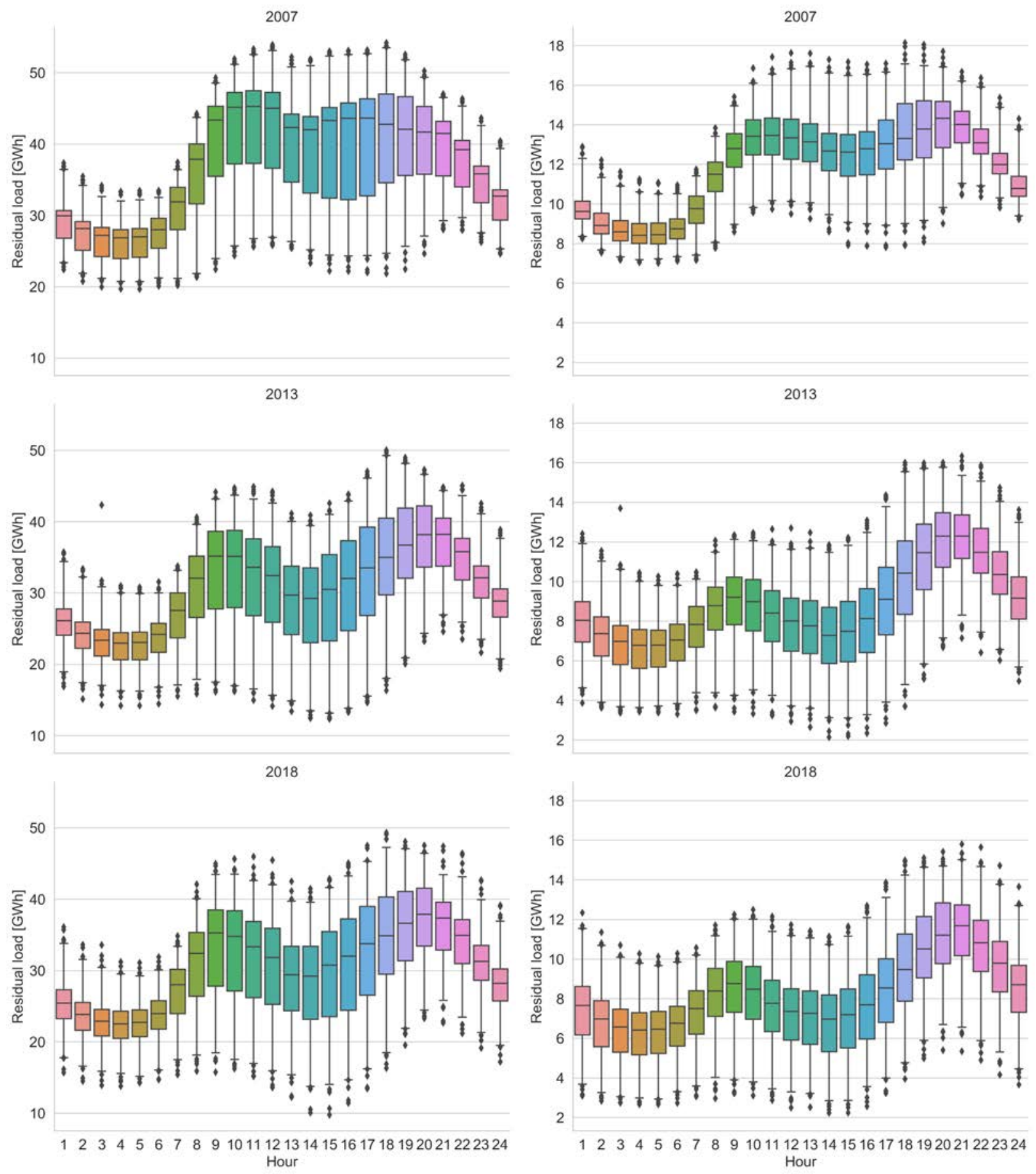

(a)

(b)

Notes: Hourly net demand in Italy (Panel a), i.e., national load minus the supply from wind and solar. Panel (b) shows the hourly net demand for the area south of Tuscany. Boxes represent interquartile range (IQR) and upper and lower vertical bars equal to the 1 percent and 99 percent. Diamonds represent outliers not included in the 1-99 percentile. Hourly data for load and wind for the year 2007 was derived from day-ahead market bidding data used in Graf and Wolak (2020). Solar generation was negligible in 2007 and zonal wind generation data was scaled to match the annual output (see https://download.terna. it/terna/0000/0113/12. pdf). Data for the years 2013 and 2018 are provided by the Italian transmission operator. 
Figure 3: Day-ahead Market vs. Real-Time Re-dispatch Market Prices

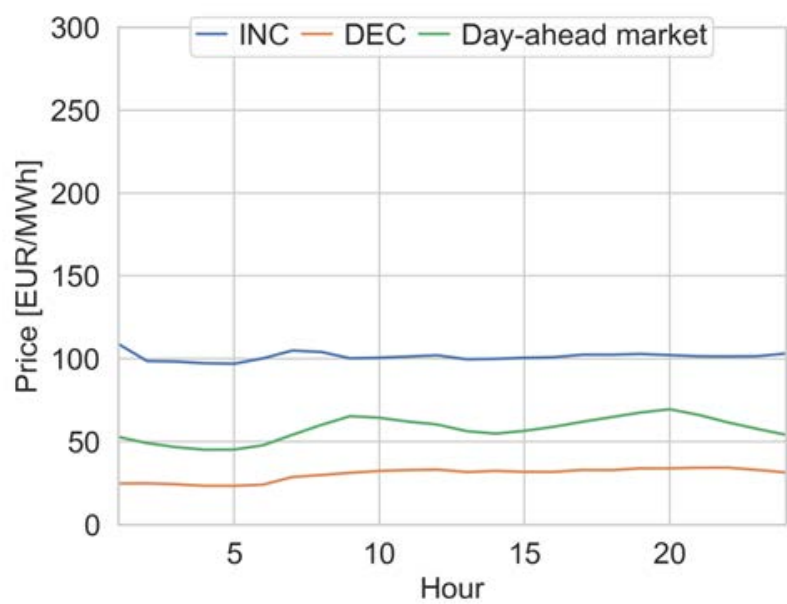

(a)

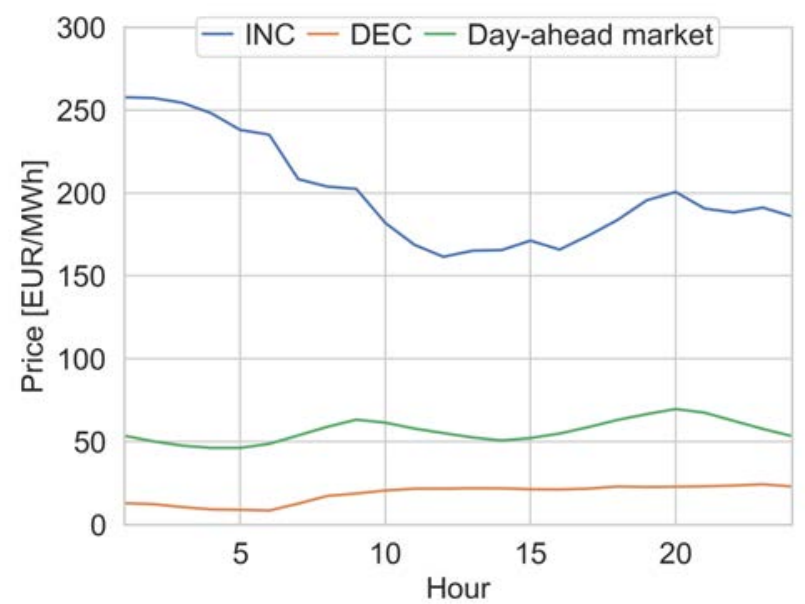

(b)

Notes: Panel (a): Northern bidding zone, Panel (b): Center-South bidding zone. The day-ahead market price is the average hourly marginal price in EUR/MWh. The INC [DEC] price is the average hourly accepted median price in EUR/MWh for INCing [DECing] output in the re-dispatch or real-time balancing market conditional on a demand for INC or DEC. Averages are taken over all hours in 2017 and 2018.

Figure 4: INC Example

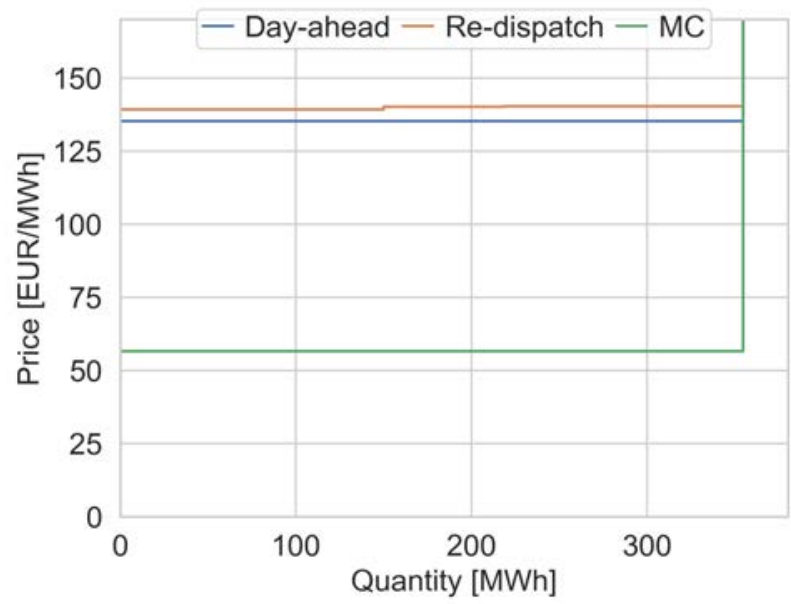

(a)

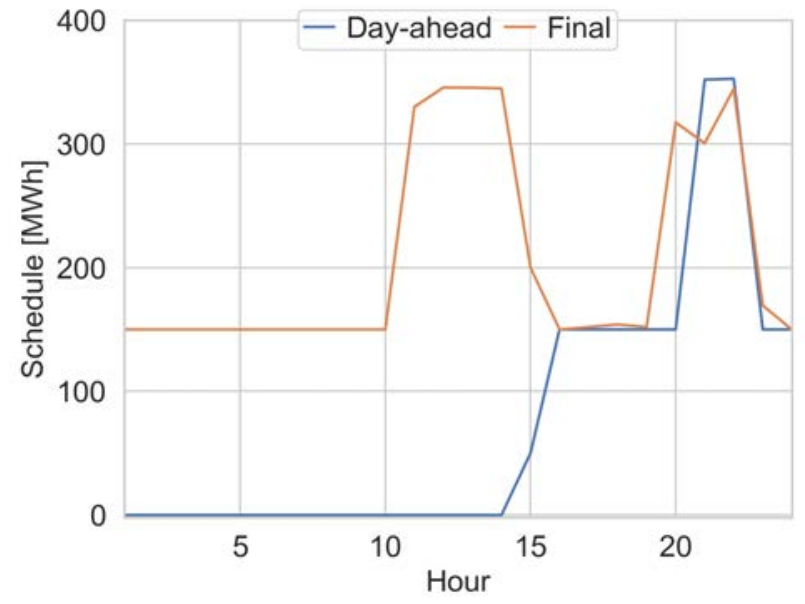

(b)

Notes: Offer behavior and schedules for a CCGT unit located in the Foggia bidding zone on April 15, 2018. Panel (a): Short-run marginal cost and offer curves in different market segments for hour 3, Panel (b): Resulting hourly schedules after each market-clearing. The offer curve in the re-dispatch market does not include the offer to provide secondary reserve. 


\section{Figure 5: DEC Example}

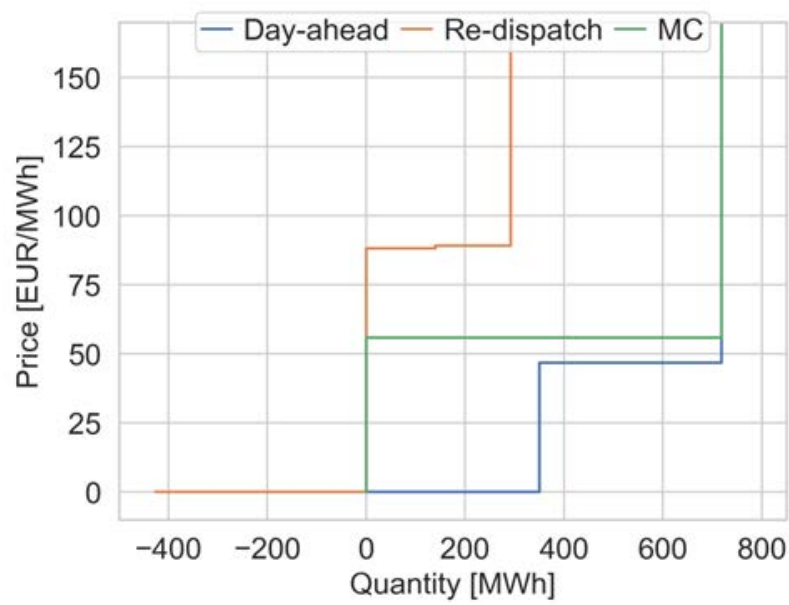

(a)

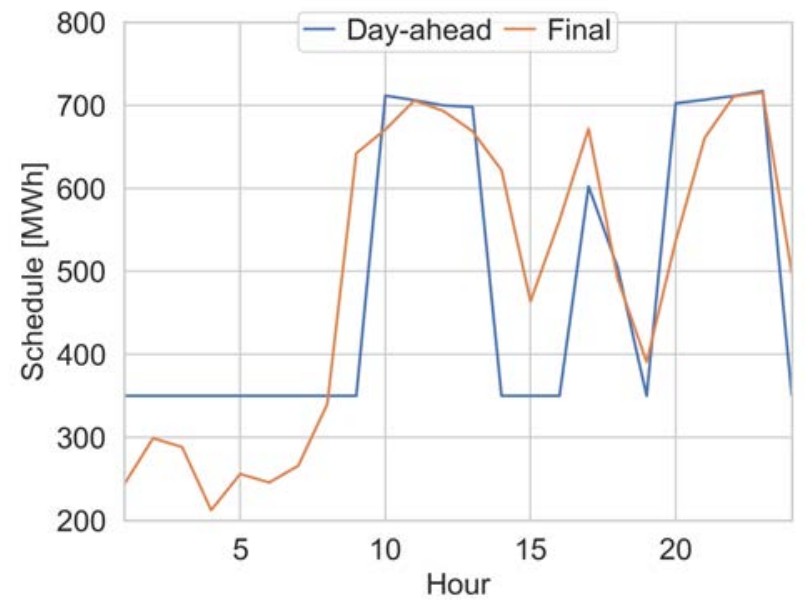

(b)

Notes: Offer behavior and schedules for a CCGT unit located in the Rossano bidding zone on April 15, 2018. Panel (a): Short-run marginal cost and offer curves in different market segments for hour 3 , Panel (b): Resulting hourly schedules after each market-clearing. The offer curve in the re-dispatch market does not include the offer to provide secondary reserve.

Figure 6: INC and DEC Quantities

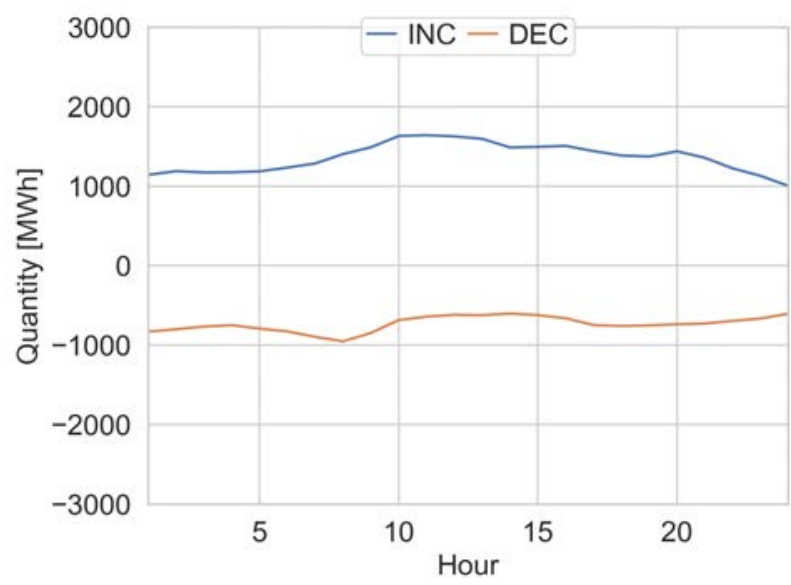

(a)

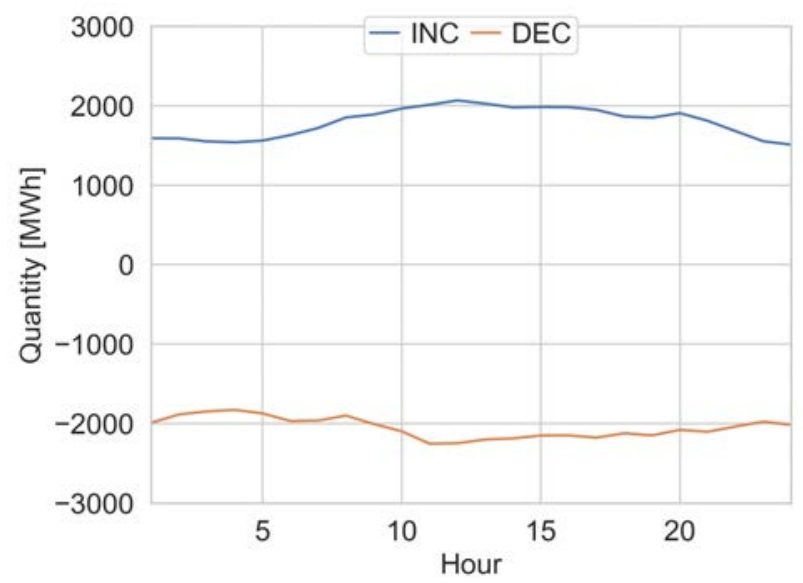

(b)

Notes: Panel (a): Accepted quantities in the re-dispatch market, Panel (b): Total INC and DEC quantities including real-time balancing market. Quantities are expressed in MWh and averages are taken over all hours in 2017 and 2018. 
Figure 7: Binscatter of Markups and Predicted Probability of getting INCed/DECed

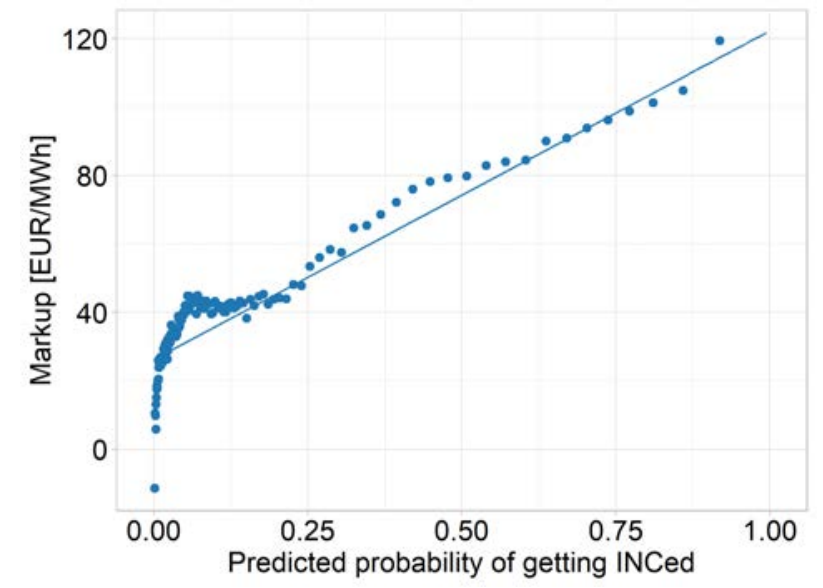

(a)

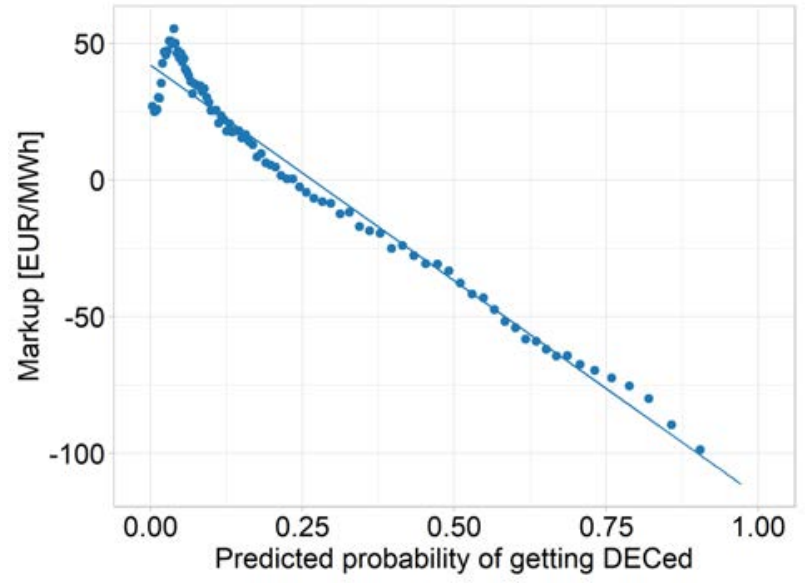

(b)

Notes: Panel (a): Day-ahead offer markup and predicted probability of getting INCed, Panel (b): Day-ahead offer markup and predicted probability of getting DECed. Markups in EUR/MWh. Binscatter regression controls for unit, hour-of-day, day-of-week and month-of-year fixed effects using Cattaneo et al. (2019) nonparametric approach. Number of bins minimizes the (asymptotic) integrated mean squared error.

Figure 8: Daily Re-dispatch Cost vs. Average Daily Net Load

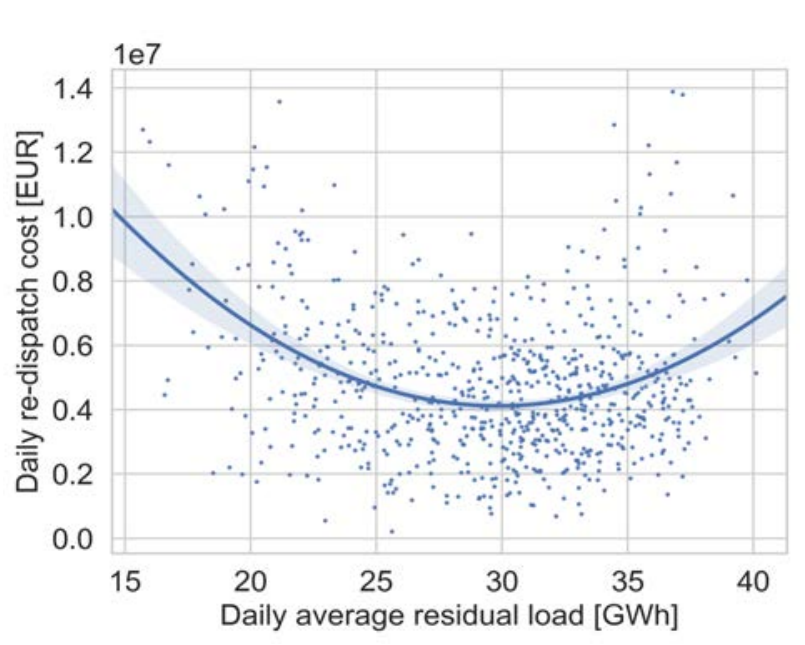

(a)

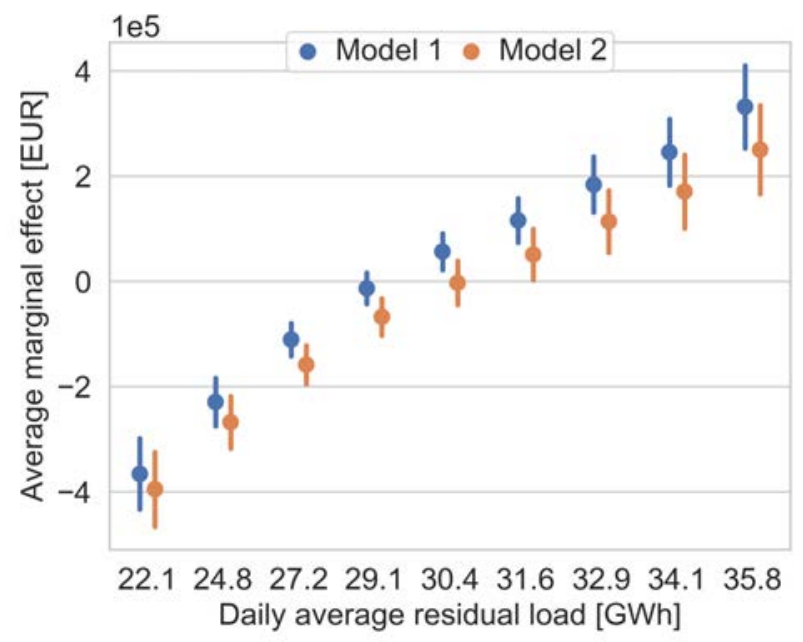

(b)

Notes: Panel (a): Average daily re-dispatch cost and average daily net load for the years 2017 and 2018 ; Panel (b) Corresponding average marginal effects of a change in the daily net load evaluated at the net load deciles. Model 1 refers to a linear regression model aiming to explain the daily re-dispatch cost by the daily average net, the square of it, and month of the sample fixed effects. In Model 2 we also include the intradaily standard deviation of the net load. Both models are summarized in Table 9, Col (2) and Col (3). 
Table 2: Regressing Markups on Predicted Probability of getting INCed or DECed

\begin{tabular}{|c|c|c|c|c|c|c|c|c|}
\hline & \multicolumn{4}{|c|}{ INC } & \multicolumn{4}{|c|}{ DEC } \\
\hline & (1) & (2) & $(3)$ & (4) & $(5)$ & $(6)$ & $(7)$ & (8) \\
\hline \multicolumn{9}{|c|}{ Panel A: All observations } \\
\hline Predicted $\mathbb{P}_{i}\left[y_{i}=1 \mid X\right]$ & $\begin{array}{r}81.37 \\
(19.89)\end{array}$ & $\begin{array}{r}88.34 \\
(16.12)\end{array}$ & $\begin{array}{r}79.35 \\
(13.87)\end{array}$ & $\begin{array}{l}103.08 \\
(17.26)\end{array}$ & $\begin{array}{r}-160.63 \\
(31.85)\end{array}$ & $\begin{array}{r}-158.78 \\
(30.35)\end{array}$ & $\begin{array}{r}-149.19 \\
(29.90)\end{array}$ & $\begin{array}{r}-159.81 \\
(28.57)\end{array}$ \\
\hline Net Load & & & & $\begin{array}{l}10.69 \\
(2.26)\end{array}$ & & & & $\begin{array}{c}-0.99 \\
(2.24)\end{array}$ \\
\hline$(\text { Net Load })^{2}$ & & & & $\begin{array}{l}-0.43 \\
(0.09)\end{array}$ & & & & $\begin{array}{l}-0.02 \\
(0.07)\end{array}$ \\
\hline$(\text { Net Load })^{3}$ & & & & $\begin{array}{r}0.00 \\
(0.00)\end{array}$ & & & & $\begin{array}{r}0.00 \\
(0.00)\end{array}$ \\
\hline Intercept & $\begin{array}{l}82.44 \\
(2.71)\end{array}$ & $\begin{array}{r}116.31 \\
(6.77)\end{array}$ & $\begin{array}{r}118.33 \\
(5.03)\end{array}$ & $\begin{array}{r}58.85 \\
(20.18)\end{array}$ & $\begin{array}{r}75.35 \\
(7.99)\end{array}$ & $\begin{array}{r}85.49 \\
(11.46)\end{array}$ & $\begin{array}{r}85.70 \\
(10.43)\end{array}$ & $\begin{array}{l}131.83 \\
(25.95)\end{array}$ \\
\hline Unit FEs & $\mathrm{X}$ & $\mathrm{X}$ & $\mathrm{X}$ & $\mathrm{X}$ & $\mathrm{X}$ & $\mathrm{X}$ & $\mathrm{X}$ & $\mathrm{X}$ \\
\hline Hour-of-day FEs & & $\mathrm{X}$ & $\mathrm{X}$ & $\mathrm{X}$ & & $\mathrm{X}$ & $\mathrm{X}$ & $\mathrm{X}$ \\
\hline Day-of-week FEs & & & & $\mathrm{X}$ & & & & $\mathrm{X}$ \\
\hline Month-of-year FEs & & $\mathrm{X}$ & $\mathrm{X}$ & $\mathrm{X}$ & & $\mathrm{X}$ & $\mathrm{X}$ & $\mathrm{X}$ \\
\hline Unit $\times$ Month FEs & & & $\mathrm{X}$ & & & & $\mathrm{X}$ & \\
\hline$N$ & 612,939 & 612,939 & 612,939 & 612,939 & 497,148 & 497,148 & 497,148 & 497,148 \\
\hline \multicolumn{9}{|c|}{ Panel B: Only observations with market-relevant transactions } \\
\hline Predicted $\mathbb{P}_{i}\left[y_{i}=1 \mid X\right]$ & $\begin{array}{l}222.24 \\
(27.35)\end{array}$ & $\begin{array}{r}216.99 \\
(28.23)\end{array}$ & $\begin{array}{r}207.61 \\
(27.43)\end{array}$ & $\begin{array}{r}217.49 \\
(28.56)\end{array}$ & $\begin{array}{l}-61.95 \\
(17.62)\end{array}$ & $\begin{array}{l}-61.10 \\
(17.17)\end{array}$ & $\begin{array}{l}-53.65 \\
(16.05)\end{array}$ & $\begin{array}{l}-63.48 \\
(17.41)\end{array}$ \\
\hline Net Load & & & & $\begin{array}{l}14.72 \\
(3.09)\end{array}$ & & & & $\begin{array}{r}0.25 \\
(1.59)\end{array}$ \\
\hline$(\text { Net Load })^{2}$ & & & & $\begin{array}{l}-0.45 \\
(0.09)\end{array}$ & & & & $\begin{array}{l}-0.01 \\
(0.06)\end{array}$ \\
\hline$(\text { Net Load })^{3}$ & & & & $\begin{array}{r}0.00 \\
(0.00)\end{array}$ & & & & $\begin{array}{r}0.00 \\
(0.00)\end{array}$ \\
\hline Intercept & $\begin{array}{l}-0.94 \\
(5.15)\end{array}$ & $\begin{array}{r}19.23 \\
(5.50)\end{array}$ & $\begin{array}{l}32.46 \\
(5.20)\end{array}$ & $\begin{array}{r}-124.24 \\
(35.27)\end{array}$ & $\begin{array}{r}7.87 \\
(5.00)\end{array}$ & $\begin{array}{l}15.03 \\
(5.77)\end{array}$ & $\begin{array}{l}-0.14 \\
(4.74)\end{array}$ & $\begin{array}{r}19.69 \\
(17.49)\end{array}$ \\
\hline Unit FEs & $\mathrm{X}$ & $\mathrm{X}$ & $\mathrm{X}$ & $\mathrm{X}$ & $\mathrm{X}$ & $\mathrm{X}$ & $\mathrm{X}$ & $\mathrm{X}$ \\
\hline Hour-of-day FEs & & $\mathrm{X}$ & $\mathrm{X}$ & $\mathrm{X}$ & & $\mathrm{X}$ & $\mathrm{X}$ & $\mathrm{X}$ \\
\hline Day-of-week FEs & & & & $\mathrm{X}$ & & & & $\mathrm{X}$ \\
\hline Month-of-year FEs & & $\mathrm{X}$ & $\mathrm{X}$ & $\mathrm{X}$ & & $\mathrm{X}$ & $\mathrm{X}$ & $\mathrm{X}$ \\
\hline Unit $\times$ Month FEs & & & $\mathrm{X}$ & & & & $\mathrm{X}$ & \\
\hline$N$ & 331,563 & 331,563 & 331,563 & 331,563 & 406,690 & 406,690 & 406,690 & 406,690 \\
\hline
\end{tabular}

Notes: The dependent variable is the markup in the day-ahead market in EUR/MWh. Net load is equal to the day-ahead forecast of the system load minus the forecast supply from wind and solar measured in GWh. Standard errors (clustered at the unit level) in parentheses. 
Table 3: Regressing Markups on Predicted Probability of getting INCed or DECed (Alternative Forecast Models)

\begin{tabular}{|c|c|c|c|c|c|c|c|c|}
\hline & \multicolumn{4}{|c|}{ INC } & \multicolumn{4}{|c|}{ DEC } \\
\hline & $(1)$ & $(2)$ & (3) & (4) & (5) & (6) & $(7)$ & (8) \\
\hline \multicolumn{9}{|c|}{ Panel A: Logit model } \\
\hline Predicted $\mathbb{P}_{i}\left[y_{i}=1 \mid X\right]$ & $\begin{array}{r}57.62 \\
(21.11)\end{array}$ & $\begin{array}{r}62.52 \\
(15.84)\end{array}$ & $\begin{array}{r}49.81 \\
(14.54)\end{array}$ & $\begin{array}{r}80.72 \\
(16.33)\end{array}$ & $\begin{array}{r}-124.93 \\
(27.00)\end{array}$ & $\begin{array}{r}-124.78 \\
(25.33)\end{array}$ & $\begin{array}{r}-103.08 \\
(26.89)\end{array}$ & $\begin{array}{r}-127.54 \\
(23.31)\end{array}$ \\
\hline Net Load & & & & $\begin{array}{r}9.00 \\
(2.19)\end{array}$ & & & & $\begin{array}{l}-1.74 \\
(2.06)\end{array}$ \\
\hline$(\text { Net Load })^{2}$ & & & & $\begin{array}{l}-0.37 \\
(0.08)\end{array}$ & & & & $\begin{array}{l}-0.03 \\
(0.07)\end{array}$ \\
\hline$(\text { Net Load })^{3}$ & & & & $\begin{array}{r}0.00 \\
(0.00)\end{array}$ & & & & $\begin{array}{r}0.00 \\
(0.00)\end{array}$ \\
\hline Unit FEs & $\mathrm{X}$ & $\mathrm{X}$ & $\mathrm{X}$ & $\mathrm{X}$ & $\mathrm{X}$ & $\mathrm{X}$ & $\mathrm{X}$ & $\mathrm{X}$ \\
\hline Hour-of-day FEs & & $\mathrm{X}$ & $\mathrm{X}$ & $\mathrm{X}$ & & $\mathrm{X}$ & $\mathrm{X}$ & $\mathrm{X}$ \\
\hline Day-of-week FEs & & & & $\mathrm{X}$ & & & & $\mathrm{X}$ \\
\hline Month-of-year FEs & & $\mathrm{X}$ & $\mathrm{X}$ & $\mathrm{X}$ & & $\mathrm{X}$ & $\mathrm{X}$ & $\mathrm{X}$ \\
\hline Unit $\times$ Month FEs & & & $\mathrm{X}$ & & & & $\mathrm{X}$ & \\
\hline$N$ & 599,148 & 599,148 & 599,148 & 599,148 & 496,258 & 496,258 & 496,258 & 496,258 \\
\hline \multicolumn{9}{|c|}{ Panel B: Linear probability model } \\
\hline Predicted $\mathbb{P}_{i}\left[y_{i}=1 \mid X\right]$ & $\begin{array}{r}55.81 \\
(25.68)\end{array}$ & $\begin{array}{r}61.54 \\
(19.14)\end{array}$ & $\begin{array}{r}44.93 \\
(19.07)\end{array}$ & $\begin{array}{r}82.55 \\
(19.43)\end{array}$ & $\begin{array}{r}-130.80 \\
(27.94)\end{array}$ & $\begin{array}{r}-131.25 \\
(26.10)\end{array}$ & $\begin{array}{r}-108.11 \\
(28.51)\end{array}$ & $\begin{array}{r}-134.42 \\
(24.01)\end{array}$ \\
\hline Net Load & & & & $\begin{array}{r}8.72 \\
(2.11)\end{array}$ & & & & $\begin{array}{l}-1.13 \\
(2.13)\end{array}$ \\
\hline$(\text { Net Load })^{2}$ & & & & $\begin{array}{l}-0.38 \\
(0.08)\end{array}$ & & & & $\begin{array}{l}-0.04 \\
(0.07)\end{array}$ \\
\hline$(\text { Net Load })^{3}$ & & & & $\begin{array}{r}0.00 \\
(0.00)\end{array}$ & & & & $\begin{array}{r}0.00 \\
(0.00)\end{array}$ \\
\hline Unit FEs & $\mathrm{X}$ & $\mathrm{X}$ & $\mathrm{X}$ & $\mathrm{X}$ & $\mathrm{X}$ & $\mathrm{X}$ & $\mathrm{X}$ & $\mathrm{X}$ \\
\hline Hour-of-day FEs & & $\mathrm{X}$ & $\mathrm{X}$ & $\mathrm{X}$ & & $\mathrm{X}$ & $\mathrm{X}$ & $\mathrm{X}$ \\
\hline Day-of-week FEs & & & & $\mathrm{X}$ & & & & $\mathrm{X}$ \\
\hline Month-of-year FEs & & $\mathrm{X}$ & $\mathrm{X}$ & $\mathrm{X}$ & & $\mathrm{X}$ & $\mathrm{X}$ & $\mathrm{X}$ \\
\hline Unit $\times$ Month FEs & & & $\mathrm{X}$ & & & & $\mathrm{X}$ & \\
\hline$N$ & 612,939 & 612,939 & 612,939 & 612,939 & 497,148 & 497,148 & 497,148 & 497,148 \\
\hline
\end{tabular}

Notes: The dependent variable is the markup in the day-ahead market in EUR/MWh. Net load is equal to the day-ahead forecast of the system load minus the forecast supply from wind and solar measured in GWh. Performing logit regressions to predict the probability of getting INCed or DECed at the unit level slightly decreases the number of observations because categories such as e.g., month-of-year, that lead to a perfect prediction are dropped from the sample. Standard errors (clustered at the unit level) in parentheses. 
Table 4: Regressing Markups on whether a Unit has been INCed or DECed (Two-Stage Least Squares)

\begin{tabular}{|c|c|c|c|c|c|c|c|c|}
\hline & \multicolumn{4}{|c|}{ INC } & \multicolumn{4}{|c|}{$\mathrm{DEC}$} \\
\hline & $(1)$ & $(2)$ & $(3)$ & $(4)$ & $(5)$ & $(6)$ & $(7)$ & $(8)$ \\
\hline \multicolumn{9}{|c|}{ Panel $A$ : Instrument is predicted $\mathbb{P}_{i}\left[y_{i}=1 \mid X\right]$ using random forest model } \\
\hline$y_{i}$ & $\begin{array}{r}53.38 \\
(12.92)\end{array}$ & $\begin{array}{r}57.70 \\
(10.47)\end{array}$ & $\begin{array}{r}50.52 \\
(8.78)\end{array}$ & $\begin{array}{r}67.05 \\
(11.12)\end{array}$ & $\begin{array}{l}-99.99 \\
(20.11)\end{array}$ & $\begin{array}{l}-97.88 \\
(18.95)\end{array}$ & $\begin{array}{l}-85.72 \\
(17.99)\end{array}$ & $\begin{array}{l}-98.47 \\
(17.81)\end{array}$ \\
\hline$N$ & 612,939 & 612,939 & 612,939 & 612,939 & 497,148 & 497,148 & 497,148 & 497,148 \\
\hline \multicolumn{9}{|c|}{ Panel $B$ : Instrument is predicted $\mathbb{P}_{i}\left[y_{i}=1 \mid X\right]$ using logit model } \\
\hline$y_{i}$ & $\begin{array}{r}57.19 \\
(20.61)\end{array}$ & $\begin{array}{r}62.05 \\
(15.44)\end{array}$ & $\begin{array}{r}49.36 \\
(14.17)\end{array}$ & $\begin{array}{r}80.03 \\
(15.92)\end{array}$ & $\begin{array}{r}-124.40 \\
(26.47)\end{array}$ & $\begin{array}{r}-124.21 \\
(24.81)\end{array}$ & $\begin{array}{r}-102.41 \\
(26.30)\end{array}$ & $\begin{array}{r}-127.24 \\
(22.83)\end{array}$ \\
\hline$N$ & 599,148 & 599,148 & 599,148 & 599,148 & 496,258 & 496,258 & 496,258 & 496,258 \\
\hline \multicolumn{9}{|c|}{ Panel $C$ : Instrument is predicted $\mathbb{P}_{i}\left[y_{i}=1 \mid X\right]$ using linear probability model } \\
\hline$y_{i}$ & $\begin{array}{r}55.81 \\
(25.36)\end{array}$ & $\begin{array}{r}61.54 \\
(18.90)\end{array}$ & $\begin{array}{r}44.93 \\
(18.82)\end{array}$ & $\begin{array}{r}82.72 \\
(19.25)\end{array}$ & $\begin{array}{r}-130.80 \\
(27.50)\end{array}$ & $\begin{array}{r}-131.25 \\
(25.69)\end{array}$ & $\begin{array}{r}-108.11 \\
(28.05)\end{array}$ & $\begin{array}{r}-134.79 \\
(23.65)\end{array}$ \\
\hline$N$ & 612,939 & 612,939 & 612,939 & 612,939 & 497,148 & 497,148 & 497,148 & 497,148 \\
\hline
\end{tabular}

Notes: The dependent variable is the markup in the day-ahead market in EUR/MWh. The four model specifications for INC and DEC correspond to the specifications in terms of fixed effects and covariates presented in Table 2. Performing logit regressions to predict the probability of getting INCed or DECed at the unit level slightly decreases the number of observations because categories such as e.g., month-of-year, that lead to a perfect prediction are dropped from the sample. Standard errors (clustered at the unit level) in parentheses.

Table 5: Markups on Predicted Probability of getting INCed or DECed using Double/Debiased Machine Learning

\begin{tabular}{lrr}
\hline & \multicolumn{1}{c}{ INC } & \multicolumn{1}{c}{ DEC } \\
\hline Predicted $\mathbb{P}_{i}\left[y_{i}=1 \mid X\right]$ & 103.7714 & -161.4813 \\
& $(0.6319)$ & $(0.6533)$ \\
$N$ & 612,939 & 497,148 \\
\hline
\end{tabular}

Notes: The dependent variable is the markup in the dayahead market in EUR/MWh. Robust standard errors in parentheses. 
Table 6: Summary of Prediction Models (Alternative Specifications)

\begin{tabular}{lcl}
\hline & INC & DEC \\
\hline \multirow{4}{*}{ Accuracy } & Panel A: Portfolio effects & \\
& 0.94 & 0.90 \\
Precision & $(0.03)$ & $(0.03)$ \\
& 0.98 & 0.93 \\
Recall & $(0.03)$ & $(0.07)$ \\
& 0.53 & 0.55 \\
& $(0.17)$ & $(0.25)$ \\
Accuracy & Panel B: Real-time re-dispatch & \\
& 0.94 & 0.86 \\
Precision & $(0.03)$ & $(0.04)$ \\
& 0.98 & 0.91 \\
Recall & $(0.03)$ & $(0.06)$ \\
& 0.50 & 0.59 \\
Panel C: Real-time & $(0.17)$ & $(0.22)$ \\
Accuracy & 0.94 & re-dispatch and portfolio \\
& $(0.03)$ & 0.87 \\
Precision & 0.98 & $(0.04)$ \\
& $(0.03)$ & 0.91 \\
Recall & 0.54 & $(0.06)$ \\
& $(0.17)$ & 0.63 \\
& & $(0.20)$ \\
\hline
\end{tabular}

Notes: Table displays mean and standard deviation (in parentheses) of unit-level predictions to be INCed or DECed across all units. Results correspond to a cross-validated random forest model. 
Table 7: Regressing Markups on Predicted Probability of getting INCed or DECed (Alternative Forecast Model Specifications)

\begin{tabular}{|c|c|c|c|c|c|c|}
\hline & \multicolumn{3}{|c|}{ INC } & \multicolumn{3}{|c|}{$\mathrm{DEC}$} \\
\hline & (1) & (2) & (3) & (4) & (5) & (6) \\
\hline \multicolumn{7}{|c|}{ Panel A: Ordinary least squares } \\
\hline Predicted $\mathbb{P}_{i}\left[y_{i}=1 \mid X\right]$ & $\begin{array}{r}90.76 \\
(20.40)\end{array}$ & $\begin{array}{r}80.62 \\
(19.67)\end{array}$ & $\begin{array}{r}90.27 \\
(20.07)\end{array}$ & $\begin{array}{r}-182.05 \\
(31.52)\end{array}$ & $\begin{array}{r}-160.16 \\
(30.06)\end{array}$ & $\begin{array}{r}-181.47 \\
(30.43)\end{array}$ \\
\hline Unit FEs & $\mathrm{X}$ & $\mathrm{X}$ & $\mathrm{X}$ & $\mathrm{X}$ & $\mathrm{X}$ & $\mathrm{X}$ \\
\hline$N$ & 612,939 & 612,939 & 612,939 & 497,148 & 497,148 & 497,148 \\
\hline \multicolumn{7}{|c|}{ Panel B: Two-stage least squares } \\
\hline$y_{i}$ & $\begin{array}{r}59.99 \\
(13.37)\end{array}$ & $\begin{array}{r}52.94 \\
(12.78)\end{array}$ & $\begin{array}{r}59.9 \\
(13.19)\end{array}$ & $\begin{array}{r}-116.54 \\
(21.16)\end{array}$ & $\begin{array}{l}-95.83 \\
(17.83)\end{array}$ & $\begin{array}{r}-112.28 \\
(19.30)\end{array}$ \\
\hline Unit FEs & $\mathrm{X}$ & $\mathrm{X}$ & $\mathrm{X}$ & $\mathrm{X}$ & $\mathrm{X}$ & $\mathrm{X}$ \\
\hline$N$ & 612,939 & 612,939 & 612,939 & 497,148 & 497,148 & 497,148 \\
\hline
\end{tabular}

Notes: The dependent variable is the markup in the day-ahead market in EUR/MWh. Standard errors (clustered at the unit level) in parentheses. Columns (1) and (4): Portfolio effects considered in the unit level forecast model. Columns (2) and (5): Real-time balancing quantities considered in the unit level forecast model. Columns (3) and (6): Portfolio effects as well as real-time balancing considered in the unit level forecast model. In Panel (B) we instrument $y_{i}$ with the predicted $\mathbb{P}_{i}\left[y_{i}=1 \mid X\right]$ derived from the random forest model. 
Table 8: Regressing Competitive Offer Share on Predicted Probability of getting INCed or DECed

\begin{tabular}{|c|c|c|c|c|c|c|c|c|}
\hline & \multicolumn{4}{|c|}{ INC } & \multicolumn{4}{|c|}{$\mathrm{DEC}$} \\
\hline & (1) & $(2)$ & (3) & $(4)$ & (5) & $(6)$ & $(7)$ & $(8)$ \\
\hline \multicolumn{9}{|c|}{ Panel A: Ordinary least squares } \\
\hline Predicted $\mathbb{P}_{i}\left[y_{i}=1 \mid X\right]$ & $\begin{array}{l}-0.37 \\
(0.08)\end{array}$ & $\begin{array}{l}-0.39 \\
(0.06)\end{array}$ & $\begin{array}{l}-0.36 \\
(0.06)\end{array}$ & $\begin{array}{l}-0.44 \\
(0.05)\end{array}$ & $\begin{array}{r}0.62 \\
(0.10)\end{array}$ & $\begin{array}{r}0.63 \\
(0.10)\end{array}$ & $\begin{array}{r}0.61 \\
(0.10)\end{array}$ & $\begin{array}{r}0.63 \\
(0.09)\end{array}$ \\
\hline Net Load & & & & $\begin{array}{l}-0.05 \\
(0.01)\end{array}$ & & & & $\begin{array}{l}-0.01 \\
(0.01)\end{array}$ \\
\hline$(\text { Net Load })^{2}$ & & & & $\begin{array}{r}0.00 \\
(0.00)\end{array}$ & & & & $\begin{array}{r}0.00 \\
(0.00)\end{array}$ \\
\hline$(\text { Net Load })^{3}$ & & & & $\begin{array}{r}0.00 \\
(0.00)\end{array}$ & & & & $\begin{array}{r}0.00 \\
(0.00)\end{array}$ \\
\hline Unit FEs & $\mathrm{X}$ & $\mathrm{X}$ & $\mathrm{X}$ & $\mathrm{X}$ & $\mathrm{X}$ & $\mathrm{X}$ & $\mathrm{X}$ & $\mathrm{X}$ \\
\hline Hour-of-day FEs & & $\mathrm{X}$ & $\mathrm{X}$ & $\mathrm{X}$ & & $\mathrm{X}$ & $\mathrm{X}$ & $\mathrm{X}$ \\
\hline Day-of-week FEs & & & & $\mathrm{X}$ & & & & $\mathrm{X}$ \\
\hline Month-of-year FEs & & $\mathrm{X}$ & $\mathrm{X}$ & $\mathrm{X}$ & & $\mathrm{X}$ & $\mathrm{X}$ & $\mathrm{X}$ \\
\hline Unit $\times$ Month FEs & & & $\mathrm{X}$ & & & & $\mathrm{X}$ & \\
\hline$N$ & 612,939 & 612,939 & 612,939 & 612,939 & 497,148 & 497,148 & 497,148 & 497,148 \\
\hline \multicolumn{9}{|c|}{ Panel B: Two-stage least squares, instrument is predicted $\mathbb{P}_{i}\left[y_{i}=1 \mid X\right]$ using random forest model } \\
\hline$y_{i}$ & $\begin{array}{l}-0.24 \\
(0.05)\end{array}$ & $\begin{array}{l}-0.26 \\
(0.04)\end{array}$ & $\begin{array}{l}-0.23 \\
(0.04)\end{array}$ & $\begin{array}{l}-0.29 \\
(0.03)\end{array}$ & $\begin{array}{r}0.39 \\
(0.06)\end{array}$ & $\begin{array}{r}0.39 \\
(0.06)\end{array}$ & $\begin{array}{r}0.35 \\
(0.06)\end{array}$ & $\begin{array}{r}0.39 \\
(0.06)\end{array}$ \\
\hline Net Load & & & & $\begin{array}{l}-0.05 \\
(0.01)\end{array}$ & & & & $\begin{array}{l}-0.01 \\
(0.01)\end{array}$ \\
\hline$(\text { Net Load })^{2}$ & & & & $\begin{array}{r}0.00 \\
(0.00)\end{array}$ & & & & $\begin{array}{r}0.00 \\
(0.00)\end{array}$ \\
\hline$(\text { Net Load })^{3}$ & & & & $\begin{array}{r}0.00 \\
(0.00)\end{array}$ & & & & $\begin{array}{r}0.00 \\
(0.00)\end{array}$ \\
\hline Unit FEs & $\mathrm{X}$ & $\mathrm{X}$ & $\mathrm{X}$ & $\mathrm{X}$ & $\mathrm{X}$ & $\mathrm{X}$ & $\mathrm{X}$ & $\mathrm{X}$ \\
\hline Hour-of-day FEs & & $\mathrm{X}$ & $\mathrm{X}$ & $\mathrm{X}$ & & $\mathrm{X}$ & $\mathrm{X}$ & $\mathrm{X}$ \\
\hline Day-of-week FEs & & & & $\mathrm{X}$ & & & & $\mathrm{X}$ \\
\hline Month-of-year FEs & & $\mathrm{X}$ & $\mathrm{X}$ & $\mathrm{X}$ & & $\mathrm{X}$ & $\mathrm{X}$ & $\mathrm{X}$ \\
\hline Unit $\times$ Month FEs & & & $\mathrm{X}$ & & & & $\mathrm{X}$ & \\
\hline$N$ & 612,939 & 612,939 & 612,939 & 612,939 & 497,148 & 497,148 & 497,148 & 497,148 \\
\hline
\end{tabular}

Notes: The dependent variable is the competitively offered quantity offered in the day-ahead market relative to the available capacity. Net load is equal to the day-ahead forecast of the system load minus the forecast supply from wind and solar measured in GWh. Standard errors (clustered at the unit level) in parentheses. 
Table 9: Daily Re-dispatch Cost and Net Load

\begin{tabular}{|c|c|c|c|}
\hline & (1) & $(2)$ & $(3)$ \\
\hline Net load & $\begin{array}{r}-45,887 \\
(16,785)\end{array}$ & $\begin{array}{r}-1,494,401 \\
(143,631)\end{array}$ & $\begin{array}{r}-1,436,106 \\
(149,020)\end{array}$ \\
\hline$(\text { Net load })^{2}$ & & $\begin{array}{r}25,478 \\
(2,514)\end{array}$ & $\begin{array}{r}23,535 \\
(2,619)\end{array}$ \\
\hline Net load SD & & & $\begin{array}{r}336,409 \\
(65,610)\end{array}$ \\
\hline Intercept & $\mathrm{X}$ & $\mathrm{X}$ & $\mathrm{X}$ \\
\hline Month of sample FEs & $\mathrm{X}$ & $\mathrm{X}$ & $\mathrm{X}$ \\
\hline Adj. $R^{2}$ & 0.40 & 0.49 & 0.51 \\
\hline$N$ & 726 & 726 & 726 \\
\hline
\end{tabular}

Notes: The dependent variable is the daily cost of re-dispatch in EUR. Net load values are daily averages expressed in GWh Net load SD is the intradaily standard deviation. Standard errors in parentheses.

Figure 9: Total Cost to Serve Load vs. Load Weighted Average Day-Ahead Market Price

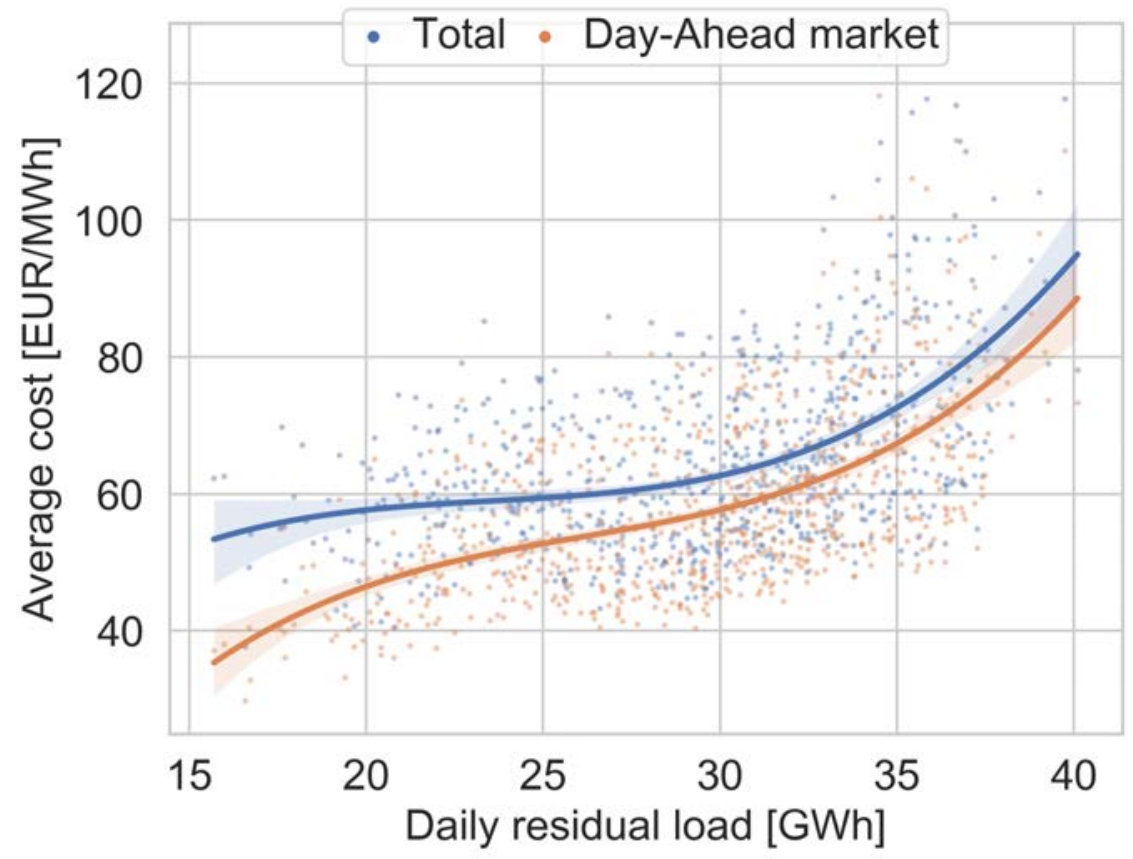

Notes: Average total cost to serve load (Total) is calculated as the demand valued at the demand-side dayahead market price plus the re-dispatch cost. This value is then divided by the demand to get an average cost per MWh demand. Demand purchased or sold in the intra-day markets is ignored. Daily averages for the years 2017 and 2018 . 


\section{References}

Bohn, Roger E, Michael C Caramanis, and Fred C Schweppe, "Optimal pricing in electrical networks over space and time," The Rand Journal of Economics, 1984, pp. 360376.

Cattaneo, Matias D., Richard K. Crump, Max H. Farrell, and Yingjie Feng, "Binscatter Regressions," Technical Report, arXiv 2019.

Chernozhukov, Victor, Denis Chetverikov, Mert Demirer, Esther Duflo, Christian Hansen, Whitney Newey, and James Robins, "Double/debiased machine learning for treatment and structural parameters," The Econometrics Journal, 2018, 21, C1C68.

Graf, Christoph and Frank A. Wolak, "Measuring the Ability to Exercise Unilateral Market Power in Locational-Pricing Markets: An Application to the Italian Electricity Market," Technical Report, Working Paper 2020.

_ , Federico Quaglia, and Frank A. Wolak, "Market Performance Assessment in Locational Markets with Non-convexities," Technical Report, Working Paper 2020.

Hirth, Lion and Ingmar Schlecht, "Redispatch Markets in Zonal Electricity Markets: Inc-Dec Gaming as a Consequence of Inconsistent Power Market Design (not Market Power)," EconStor Preprints 194292, ZBW - Leibniz Information Centre for Economics 2019.

Ito, Koichiro and Mar Reguant, "Sequential Markets, Market Power, and Arbitrage," American Economic Review, 2016, 106 (7), 1921-1957.

Open Power System Data, "Data Package Time series," 2019. Version 2019-06-05.

Wozabal, David, Christoph Graf, and David Hirschmann, "The effect of intermittent renewables on the electricity price variance," OR Spectrum, 2016, 38 (3), 687-709. 


\section{A Additional Econometric Analyses}

In this Section, we extend the empirical analysis presented in Section 5 by enlarging the sample size. Instead of selecting only combined cycle units that historically did the most INC and DEC action, we now use all combined cycle units that are eligible to participate in the re-dispatch market and do not have cost-of-service contracts with the transmission operator. Excluding the set of units with such contracts is reasonable as these units are obliged to either offer their available capacity at their short-run marginal cost or at zero to the day-ahead market. Hence, even if there were a positive likelihood of getting INCed or DECed in the re-dispatch market, these units are not able to take advantage of it. Our sample comprises now 76 units for the INC product and 73 for the DEC product. The reason why the number of units in the INC category is different from the number of units in the DEC category is that we require at least two instances of an INC or a DEC for each category.

The statistical analysis presented in Table 10, Panel A, is broadly similar to that presented in Table (2), Panel A, with the only difference that we now consider the full set of units. The qualitative interpretation does not change. The only difference is that the coefficients of the INC side are smaller than before but still statistically significant. The results also hold when instrumenting for the indicator variable for whether a unit is INCed or DECed using the predicted probability as instrument (compare Table 10, Panel B, with Table 4, Panel A). 


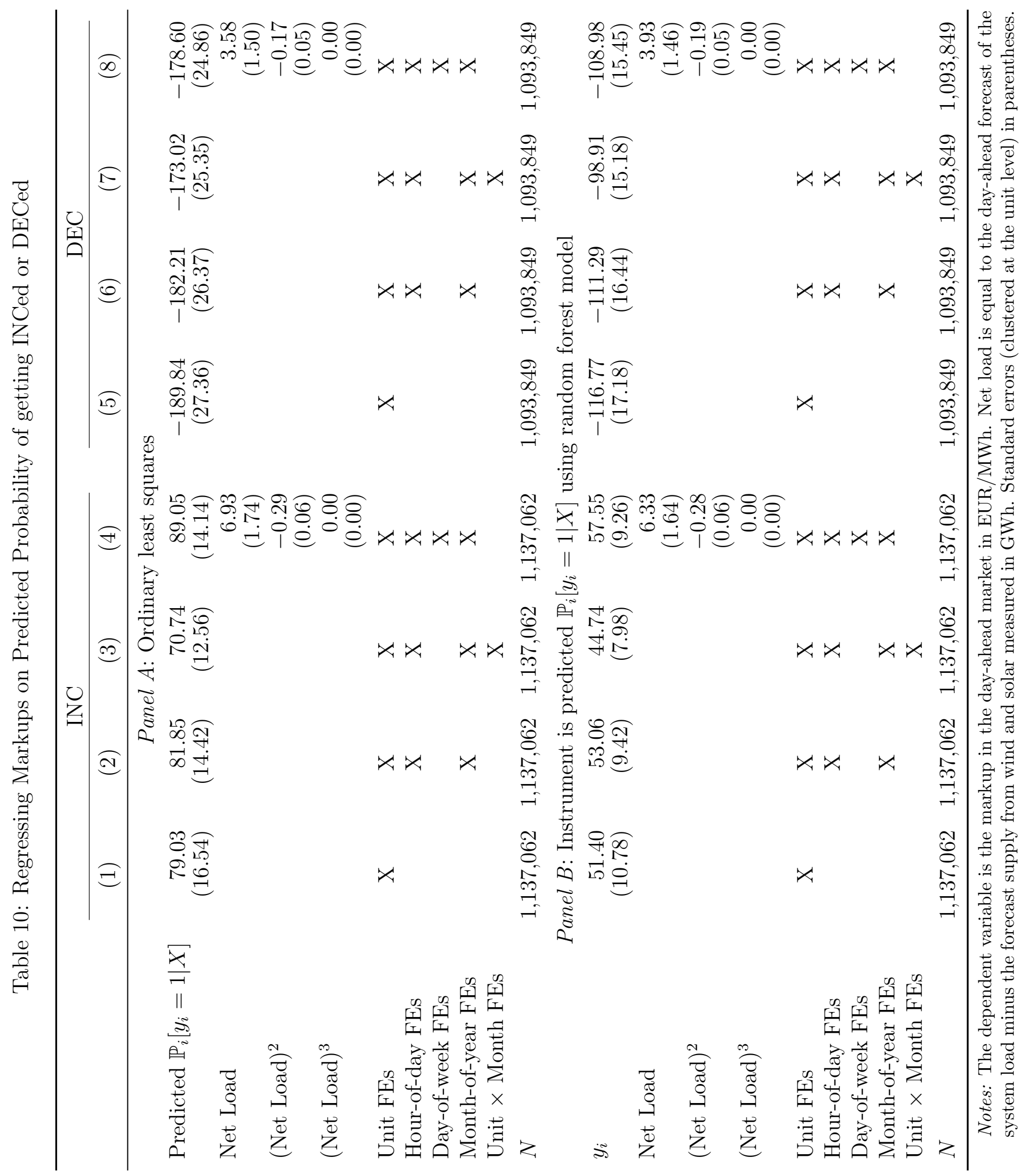


Table 11: Regressing Markups on Predicted Probability of getting INCed or DECed (Ignoring Renewable Generation forecast data in Prediction Models)

\begin{tabular}{|c|c|c|c|c|}
\hline & \multicolumn{2}{|c|}{ INC } & \multicolumn{2}{|c|}{ DEC } \\
\hline & (1) & $(2)$ & (3) & $(4)$ \\
\hline \multicolumn{5}{|c|}{ Panel A: Ordinary least squares } \\
\hline Predicted $\mathbb{P}_{i}\left[y_{i}=1 \mid X\right]$ & $\begin{array}{r}86.25 \\
(21.75)\end{array}$ & $\begin{array}{r}86.29 \\
(18.60)\end{array}$ & $\begin{array}{r}-168.73 \\
(33.20)\end{array}$ & $\begin{array}{r}-200.03 \\
(28.40)\end{array}$ \\
\hline Unit FEs & $\mathrm{X}$ & $\mathrm{X}$ & $\mathrm{X}$ & $\mathrm{X}$ \\
\hline$N$ & 612,939 & $1,137,062$ & 497,148 & $1,093,849$ \\
\hline \multicolumn{5}{|c|}{ Panel B: Two-stage least squares } \\
\hline$y_{i}$ & $\begin{array}{r}57.78 \\
(14.44)\end{array}$ & $\begin{array}{r}56.45 \\
(12.19)\end{array}$ & $\begin{array}{r}-107.46 \\
(21.54)\end{array}$ & $\begin{array}{r}-125.85 \\
(18.31)\end{array}$ \\
\hline Unit FEs & $\mathrm{X}$ & $\mathrm{X}$ & $\mathrm{X}$ & $\mathrm{X}$ \\
\hline$N$ & 612,939 & $1,137,062$ & 497,148 & $1,093,849$ \\
\hline
\end{tabular}

Notes: The dependent variable is the markup in the day-ahead market in EUR/MWh. Standard errors (clustered at the unit level) in parentheses. Columns (1) and (3): most important CCGT units; Columns (2) and (4): all eligible CCGT units. In Panel (B) we instrument $y_{i}$ with the predicted $\mathbb{P}_{i}\left[y_{i}=1 \mid X\right]$ derived from the random forest model. 